\title{
Selective Growth of Low Stored Energy Grains During $\delta$ Sub-solvus Annealing in the Inconel 718 Nickel-Based Superalloy
}

\author{
ANDREA AGNOLI, MARC BERNACKI, ROLAND LOGÉ, \\ JEAN-MICHEL FRANCHET, JOHANNE LAIGO, and NATHALIE BOZZOLO
}

The microstructure stability during $\delta$ sub-solvus annealing in Inconel 718 was investigated, focusing on the conditions that may lead to the development of very large grains (about $100 \mu \mathrm{m}$ ) in a recrystallized fine grained matrix ( 4 to $5 \mu \mathrm{m}$ ) despite the presence of second-phase particles. Microstructure evolution was analyzed by EBSD (grain size, intragranular misorientation) and SEM ( $\delta$ phase particles). Results confirm that, in the absence of stored energy, the grain structure is controlled by the $\delta$ phase particles, as predicted by the Smith-Zener equation. If the initial microstructure is strained $(\varepsilon<0.1)$ before annealing, then low stored energy grains grow to a large extent, despite the Zener pinning forces exerted by the second-phase particles on the grain boundaries. Those selectively growing grains could be those of the initial microstructure that were the least deformed, or they could result from a nucleation process. The balance of three forces acting on boundary migration controls the growth process: if the sum of capillarity and stored energy driving forces exceeds the Zener pinning force, then selective grain growth occurs. Such phenomenon could be simulated, using a level set approach in a finite element context, by taking into account the three forces acting on boundary migration and by considering a realistic strain energy distribution (estimated from EBSD measurements).

DOI: $10.1007 / \mathrm{s} 11661-015-3035-9$

(C) The Minerals, Metals \& Materials Society and ASM International 2015

\section{INTRODUCTION}

THE mechanical properties of Inconel 718, that is widely used for aircraft engine parts, are greatly influenced by the microstructure that has to be fine and homogenous to ensure the required performance is achieved in service conditions. For example, fatigue resistance is a critical attribute that is affected by the heterogeneity of the grain structure. ${ }^{[1-3]}$ Hence, microstructure evolution during metal forming is of particular importance. The stability of the microstructure has to be under control during each stage of thermomechanical processing, notably during the annealing stages. All nickel-based superalloys contain secondary-phase particles that can be exploited to limit grain growth during annealing through the Smith-Zener pinning effect. ${ }^{[4,5]}$ In the case of Inconel 718 , the presence of $\delta$ phase particles $\left(\mathrm{Ni}_{3} \mathrm{Nb}\right)$ hinders grain growth during $\delta$

ANDREA AGNOLI, JEAN-MICHEL FRANCHET, and JOHANNE LAIGO, Materials Engineers, are with the Snecma Gennevilliers, 171 boulevard Valmy, 92702 Colombes, France. Contact e-mail: andrea.agnoli@snecma.fr MARC BERNACKI and NATHALIE BOZZOLO, Professors, are with the Mines ParisTech, PSL - Research University, CEMEF - Centre de Mise en Forme des Matériaux, CNRS UMR 7635, CS 10207, rue Claude Daunesse, 06904 Sophia Antipolis Cedex, France. ROLAND LOGÉ, formerly Professor with the Mines ParisTech, PSL - Research University, CEMEF - Centre de Mise en Forme des Matériaux, CNRS UMR 7635, is now with the Thermomechanical Metallurgy Laboratory - PX Group Chair, Ecole Polytechnique Fédérale de Lausanne (EPFL), Rue de la Maladiére 71B - CP 526, 2002 Neuchâtel, Switzerland.

Manuscript submitted January 11, 2015.

Article published online July 8, 2015 sub-solvus annealing. ${ }^{[6]}$ Nonetheless, during complex hot forging cycles, critical thermomechanical conditions can result in what has been referred to as abnormal grain growth during $\delta$ sub-solvus annealing stages. ${ }^{[2]}$ Despite the obvious industrial interest for understanding the origin of this phenomenon in order to avoid it, there are only very few studies addressing this problem in Inconel 718 alloy. ${ }^{[2,3,7]}$ According to these studies, abnormal grain growth is not caused by local depletions of $\delta$ phase particles or by texture effects. On the contrary, the phenomenon seems to be initiated by small prior strains, but the underlying microstructural mechanisms were not investigated ${ }^{[2,3]}$ or they were only partially observed in one experimental condition. ${ }^{[7]}$ It is worth mentioning that, since strain seems to be involved in the control of the phenomenon, the term abnormal grain growth is, strictly speaking, inappropriate. It was nevertheless used because the resulting possibly bimodal grain size distributions are very similar to those of abnormally grown microstructures.

The aim of this paper is to discuss the influence of different microstructural features (in particular $\delta$ phase particles and deformation stored energy) on the occurrence of that strain-induced selective grain growth during $\delta$ sub-solvus annealing in Inconel 718 superalloy.

\section{EXPERIMENTAL PROCEDURE}

The Inconel 718 material used in this study was fully recrystallized and has been provided by Snecma, and the chemical composition is reported in Table I. Torsion 
Table I. Chemical Composition of the Inconel 718 Piece (Weight Percent)

\begin{tabular}{lcccccr}
\hline $\mathrm{Ni}$ & $\mathrm{Cr}$ & $\mathrm{Fe}$ & $\mathrm{Nb}$ & $\mathrm{Mo}$ & $\mathrm{Ti}$ & $\mathrm{Al}$ \\
\hline Bal. & 18 & 17.44 & 5.39 & 2.96 & 1.01 & 0.46 \\
\hline $\mathrm{Co}$ & $\mathrm{Mn}$ & $\mathrm{Si}$ & $\mathrm{Cu}$ & $\mathrm{C}$ & $\mathrm{Ta}$ & $\mathrm{B}$ \\
\hline 0.14 & 0.09 & 0.08 & 0.03 & 0.02 & 0.01 & 0.004 \\
\hline
\end{tabular}

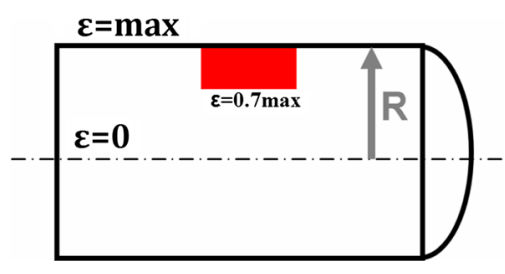

Fig. 1-Scheme of torsion sample sectioning. The zone analyzed by EBSD is shown as a red box (Color figure online).

samples were machined, with a gage length of $15 \mathrm{~mm}$ and a radius of $3 \mathrm{~mm}$. All samples except one were hot deformed $\left(\varepsilon_{\mathrm{MAX}}=0.05,0.1\right.$, and 0.3$)$ at $1258 \mathrm{~K}$ $\left(985^{\circ} \mathrm{C}\right)$ and then water quenched to characterize the microstructure. Finally, samples were annealed at $1258 \mathrm{~K}\left(985^{\circ} \mathrm{C}\right)$ for 2 hours in an electrical furnace to investigate the microstructure evolution. It is noted that at $1258 \mathrm{~K}\left(985^{\circ} \mathrm{C}\right), \gamma^{\prime}$ and $\gamma^{\prime \prime}$ hardening particles are dissolved, while existing $\delta$ phase particles can coarsen and new particles can be precipitated. Few carbides and nitrides are also present; however, their effect on microstructure evolution is negligible due to the very low content (around 0.1 vol pct).

For characterization, samples were cut in half along the axial direction: this sectioning procedure (see Figure 1) allows one to analyze, on the same section, a continuous range of strain (and strain rate), which reaches a maximum at the surface (at radius $=3 \mathrm{~mm}$ ) and then decreases linearly along the radius down to 0 (at radius $=0$, i.e., at the neutral axis of the torsion test sample). In fact, for each sample, two areas have been quantitatively analyzed at the top and bottom of the large EBSD map covering the range of radius $=2.2$ to $3 \mathrm{~mm}$ : one area is close to the sample surface where the strain is maximum and the other is located at a distance of $0.8 \mathrm{~mm}$ from the surface where the strain is about 70 pct of the maximum strain. Then samples were prepared for SEM (ZEISS SUPRA 40 FEG) and EBSD (Bruker CrystAlign) characterization. The preparation consisted of mechanical grinding, followed by fine polishing and finally vibration polishing for at least 12 hours (using a $\mathrm{SiO}_{2}$ colloidal suspension).

The fraction and morphology of $\delta$ phase particles were determined by image analysis using the UTHSCSA Image Tool software. At least five BSE (back-scattered electrons) images per sample (after polishing as described above, i.e., without etching) were analyzed, each image corresponding to an area of $100 \times 150 \mu \mathrm{m}$. Grain size and intragranular misorientation were determined by analyzing EBSD datasets using the TSL OIM Analysis software. EBSD maps were acquired choosing an appropriate step size $(0.2$ to $1 \mu \mathrm{m})$ for each microstructure scale, each map containing about 1000 grains. The EBSD measurement angular resolution can be estimated to be about $0.5 \mathrm{deg}$ under the configuration employed in the present study. For the detection of grains, a maximum misorientation angle of $5 \mathrm{deg}$ was accepted between neighboring pixels belonging to the same grain and twin boundaries (defined by a misorientation of $60 \mathrm{deg}$ along the axis $\langle 111\rangle$ with a tolerance of $5 \mathrm{deg}$ ) were ignored. In all the reported results, the average grain size is calculated as the arithmetic mean (i.e., number-weighted average) of the diameters of circles having the same area as the measured grains.

Intragranular misorientation was estimated either by calculating the GOS (Grain Orientation Spread) or the GAM (Grain Average Misorientation) parameter provided by the OIM software. These parameters were chosen to provide relative information about the hardening state of individual grains, as the intragranular misorientations of grains can be related to the density of geometrically necessary dislocations (GNDs). The GOS is the average misorientation angle between each measured point (in a grain) and the average grain orientation. Thus, it does not depend on the step size and it takes into account long-range orientation gradients. The GAM is the average misorientation angle of all pairs of neighboring pixels in a grain. It depends on the step size as it is based on neighboring point-to-point misorientations: therefore, when using this parameter, the step size must be also specified (which is rarely the case in the literature).

\section{MICROSTRUCTURE EVOLUTION DURING $\triangle$ SUB-SOLVUS ANNEALING}

\section{A. Initial Microstructure}

The main properties of the initial microstructure of the Inconel 718 piece are reported in Figure 2. The microstructure is almost fully (90 pct volume fraction) recrystallized and equiaxed, and the average grain size is $4.6 \mu \mathrm{m}$ (see Figure 2(a)). Nonetheless, it is possible to note the presence of few bigger not recrystallized grains $(\sim 30 \mu \mathrm{m})$. The GOS distribution is centered at about $0.5 \mathrm{deg}$ (see Figure 2(b)), a value which is close to the actual EBSD angular resolution. As the distribution is also very narrow, it can be considered that roughly 90 pct of the microstructure is made of strain-free recrystallized grains. The rest of the grains are more or less hardened: in particular, hardened grains with GOS higher than 3 deg are clearly the larger unrecrystallized grains (see Figure 2(c)).

The average $\delta$ phase surface fraction (that coincides with the volume fraction if the overall analyzed area is 


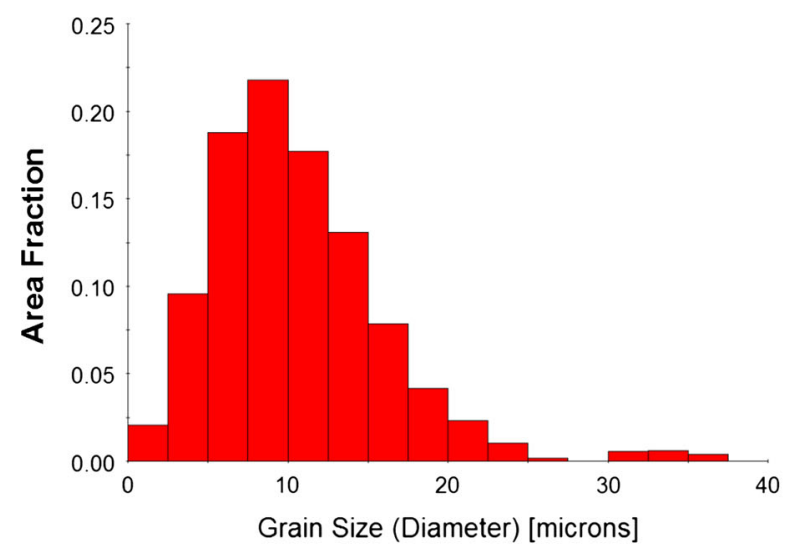

(a)

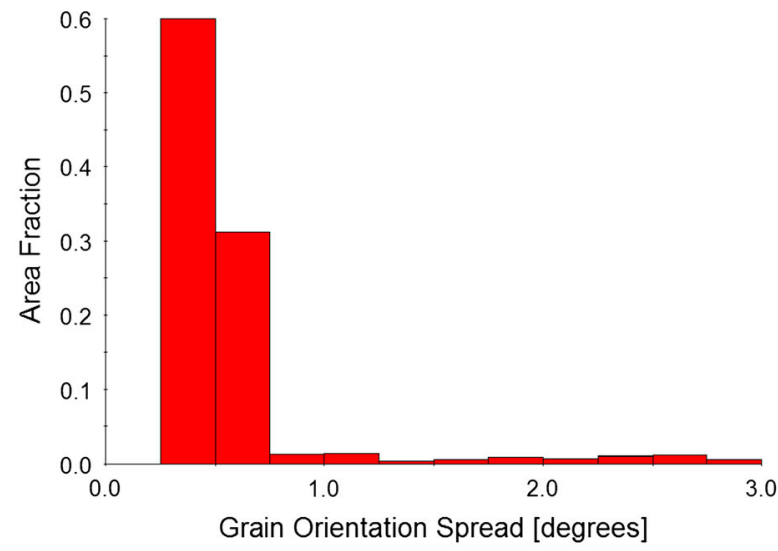

(b)

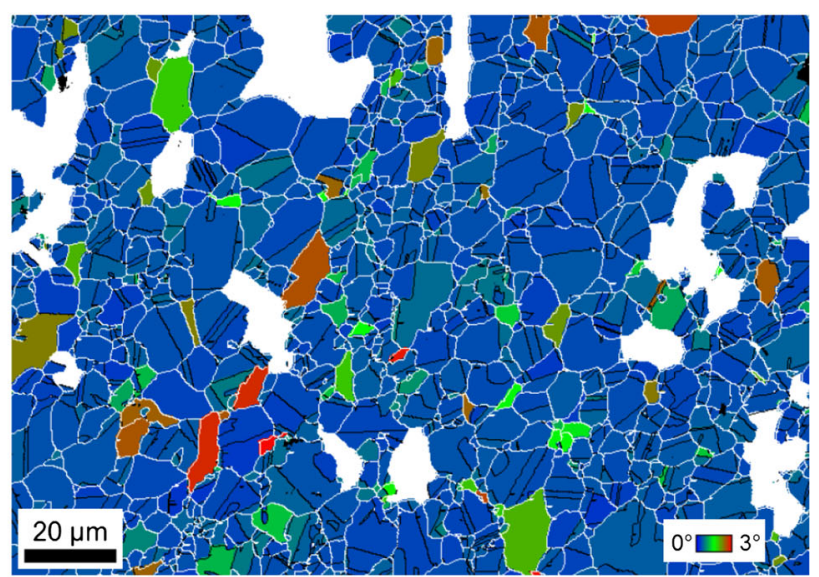

(c)

Fig. 2-Initial microstructure properties determined by EBSD measurements. Grain size distribution histogram $(a)$. GOS distribution histogram $(b)$. EBSD map $(c)$ : grain boundaries in white, twins in black, and grain colors related to GOS values (white grains have higher GOS values than $3 \mathrm{deg}$ ) (Color figure online).

large enough) was found to be in the range of $1.7 \pm 0.3$ pct. Figure 3 shows that the distribution and morphology of the particles is quite heterogeneous. Notably, if the distribution of the minor axis (or width) of particles is centered around the average value $(0.3 \mu \mathrm{m})$, the distribution of the major axis (length) is wider and spans up to $3 \mu \mathrm{m}$.

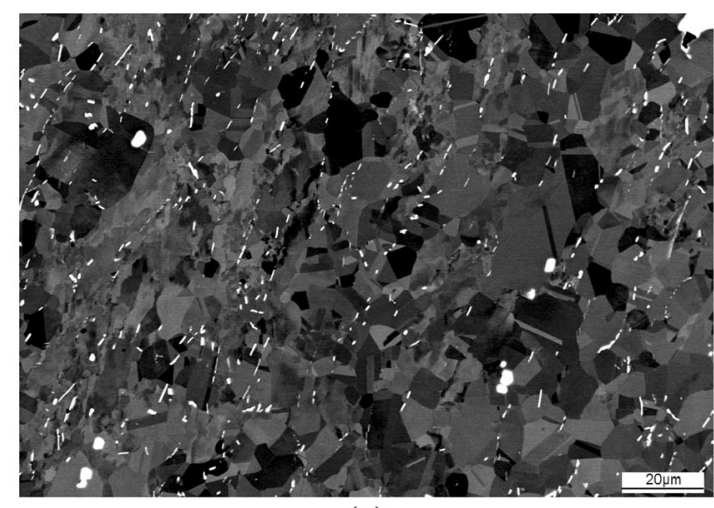

(a)

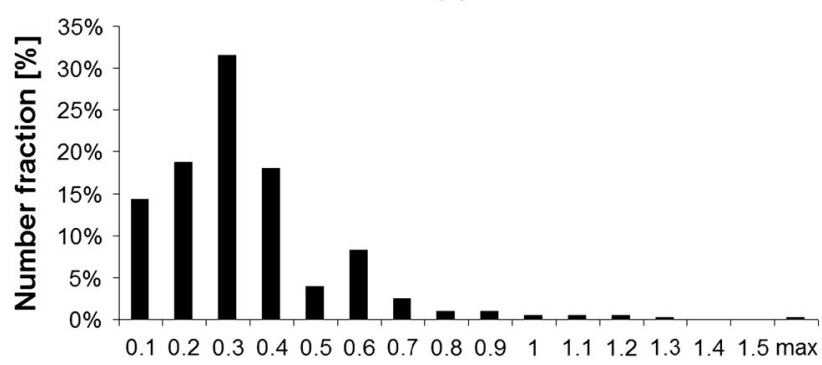

Particle minor axis $[\mu \mathrm{m}]$

(b)

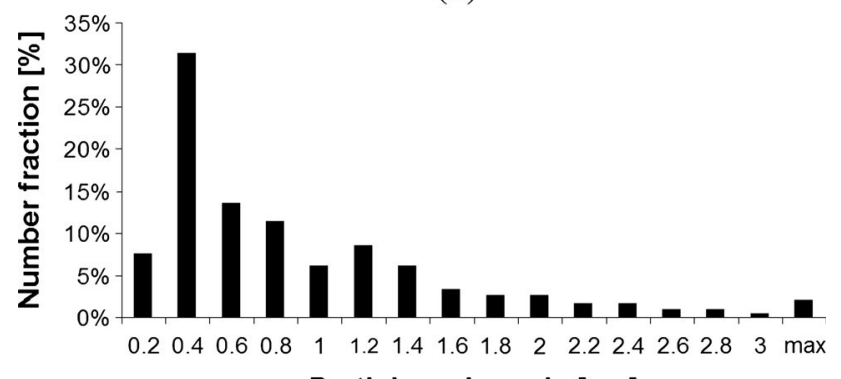

Particle major axis $[\mu \mathrm{m}]$

(c)

Fig. 3-Distribution of the $\delta$ phase in the initial microstructure: $(a)$ BSE image showing the $\delta$ phase as small white particles and few carbides (NbC) as bigger particles, $(b)$ minor axis, and $(c)$ major axis particle number fraction.

\section{B. Stability of the Initial Microstructure and Smith- Zener Pinning}

A sample of the initial microstructure was $\delta$ subsolvus annealed at $1258 \mathrm{~K}\left(985^{\circ} \mathrm{C}\right)$ for 2 hours to investigate the stability of the microstructure. Figure 4 suggests that there was only little grain growth despite the high temperature and prolonged annealing time. The average grain size increases from 4.6 to $7.2 \mu \mathrm{m}$ (see Table II). In fact, as it is well known that the presence of $\delta$ phase particles in Inconel 718 can hinder grain growth. The involved phenomenon is known as Smith-Zener pinning, and the relation between the stable grain size and the second-phase population can be described by the following simple equation: ${ }^{[8]}$

$$
D=\alpha \frac{4 r}{3} \frac{r}{f},
$$


where $D$ corresponds to the average diameter of (randomly distributed spherical) grains, $\mathrm{r}$ and $\mathrm{f}$ are, respectively, the average radius and volume fraction of (spherical) secondary-phase particles, and $\alpha$ is a constant $(0.25<\alpha<0.5)$. The value of the parameter $\alpha$ is influenced by the microstructure properties (boundary energies and average curvature, particle distribution and shape, etc.). For example, rod-shaped particles ${ }^{[9]}$ or coherent particles ${ }^{[10]}$ are more effective to pin grain boundaries, and then $\alpha$ is smaller. As shown in Figure 3, the real $\delta$ phase morphology is quite variable and some

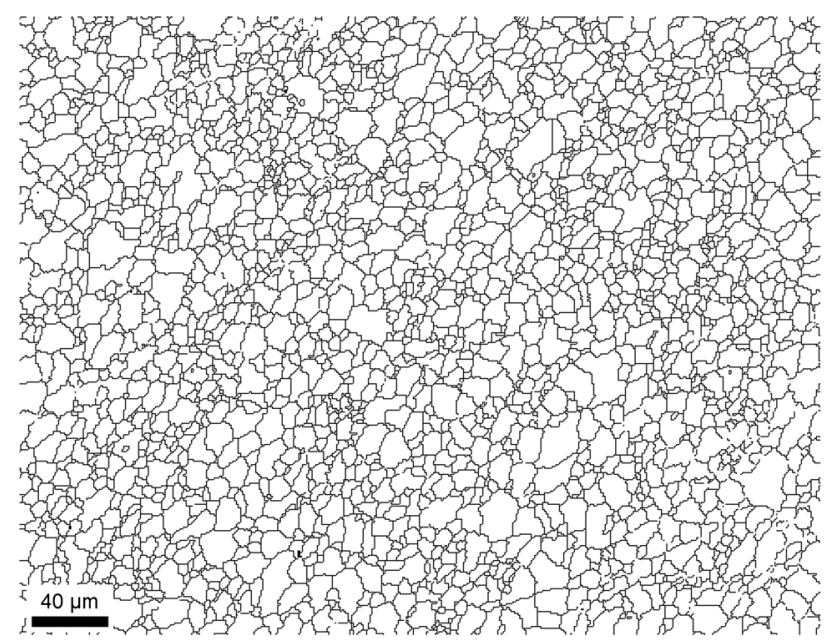

(a)

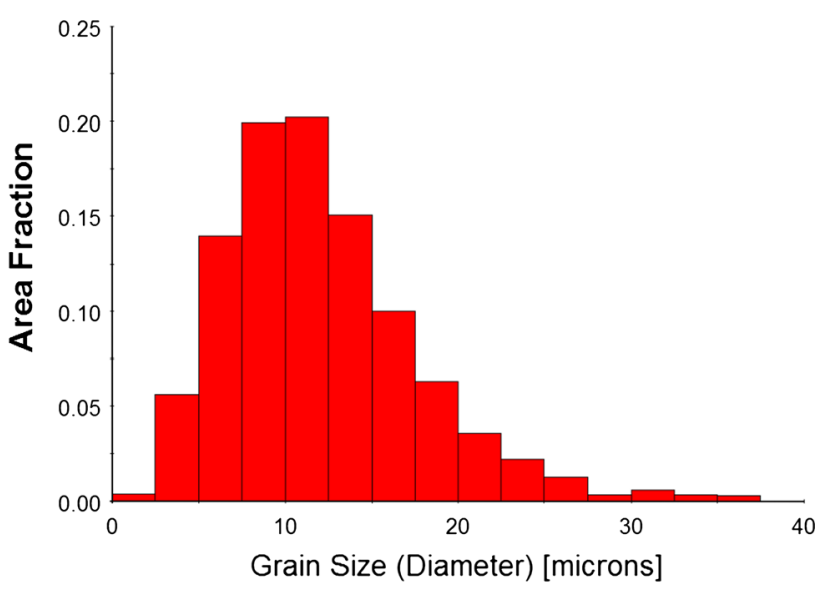

(b)

Fig. 4 - Grain size distribution determined by EBSD in the initial microstructure after $\delta$ sub-solvus annealing for $2 \mathrm{~h}$ : $(a)$ grain boundaries in black (twins excluded), (b) grain size distribution histogram. particles can be hardly considered as spheres. Nonetheless, in order to overcome this problem, it is proposed to evaluate the equivalent radius of spherical particles having the same volume as experimental particles. Then, under this assumption, it is possible to plot Eq. [1] as a function of the experimental $\delta$ phase volume fraction. Figure 5 indicates that the experimental data obtained after annealing the initial microstructure (black triangle symbol) respects Eq. [1] by falling in between the two curves. Then, despite the simplicity and all the assumptions behind Eq. [1], it characterizes the pinning behavior and rationalizes why significant grain growth did not occur after annealing. A more detailed analysis of the microstructure by SEM (see Figure 6) suggests that few grains could nevertheless grow, surpassing the SmithZener limit, but only in regions where the local fraction of particles was much lower compared to the average value. Figure 6 also reveals that after annealing, the average $\delta$ phase fraction is higher (about $4 \pm 0.5$ pct) compared to the value in the initial state (about $1.7 \pm 0.3 \mathrm{pct}$ ) shown in Figure 3 . In fact, during $\delta$ sub-solvus annealing particles precipitate (mostly at grain boundaries) and grow. Hence, the lower particle density inside coarser grains could also be the consequence and not the origin of such larger grains. It is worth also noting that (as it will be shown in the next section for sample $\varepsilon=0.05$ ) such larger grains are not growing anymore even if annealing is prolonged for additional two hours at $1258 \mathrm{~K}\left(985^{\circ} \mathrm{C}\right)$.

\section{Influence of Hardening on Microstructure Stability}

The influence of strain on the stability of the initial microstructure during $\delta$ sub-solvus annealing at $1258 \mathrm{~K}$ $\left(985^{\circ} \mathrm{C}\right.$ ) for 2 hours was investigated. Three torsion samples were first strained by hot torsion at $1258 \mathrm{~K}$ $\left(985^{\circ} \mathrm{C}\right.$ ) reaching an equivalent $\max$ strains (at radius $=3 \mathrm{~mm}$ ) of, respectively, $0.05,0.1$, and 0.3 . Then, samples were water quenched to room temperature to be characterized. Finally, samples were $\delta$ subsolvus annealed for 2 hours. As shown in Table II, the microstructure of the strained samples just after quenching does not differ much from the initial microstructure in terms of grain size and $\delta$ phase distribution. More precisely, the average grain size was about $5 \mu \mathrm{m}$, and that similar morphology of particles and a $\delta$ phase fraction in the range of 1 to 2 pct were found. However, the average intragranular misorientation in strained samples is higher and increases with strain. Figure 7(c) illustrates that the average GOS for $\varepsilon=0.05$ is slightly higher compared to the one of the initial microstructure

Table II. Summary of Microstructural Properties of Samples (Measured in the Whole Region Defined by $2.7 \mathrm{~mm}$ $<$ radius $<3 \mathrm{~mm}$ ) Before and After Annealing: The Equivalent Circular Radius of $\delta$ Phase Particles is Around $0.25 \mu \mathrm{m}$ in All Samples

\begin{tabular}{lccc}
\hline & $\varepsilon=0$ & $\varepsilon=0.05$ & $\varepsilon=0.1$ \\
\hline Before Annealing & & & \\
Average $\delta$ phase fraction $(\mathrm{pct})$ & 1.7 & 1.0 & 2.2 \\
Average grain diameter $(\mu \mathrm{m})$ & 4.6 & 5.2 & 4.6 \\
After Annealing & 7.2 & 7.3 & 4.0 \\
Average grain diameter $(\mu \mathrm{m})$ & & $47(6.2)$ & 13.3 \\
\hline
\end{tabular}




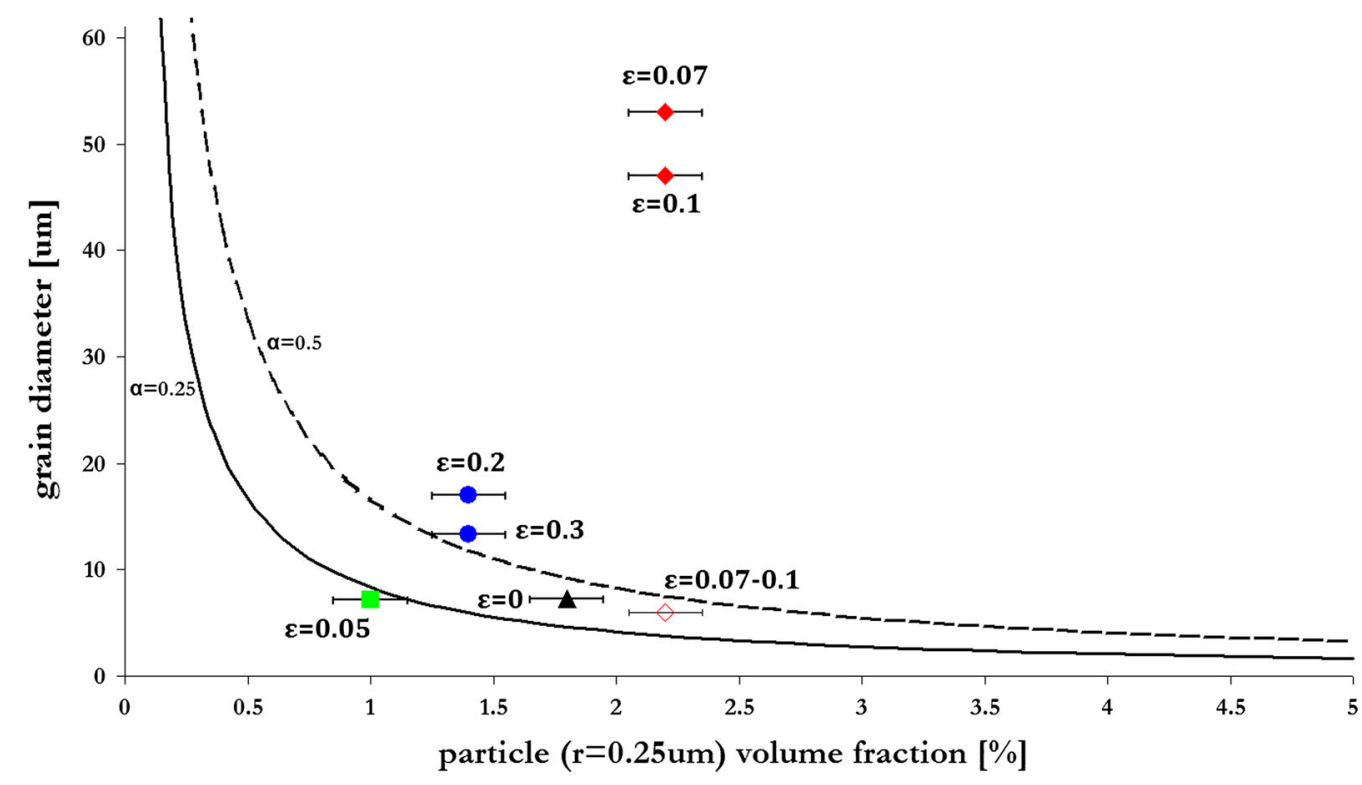

Fig. 5-Comparison of grain size predicted by Eq. [1] and values measured on samples characterized by different initial levels of strain $(0<\varepsilon<0.3)$ after $\delta$ sub-solvus annealing for $2 \mathrm{~h}$. The empty square corresponds to the minor population of bimodal microstructures in samples $\varepsilon=0.07$ and $\varepsilon=0.1$. Note: the $\delta$ phase fraction is measured before annealing.

(see Figure 2). But, as strain increases, the GOS distribution widens and it shifts toward higher misorientation angles. Notably, GOS maps can reveal differences in hardened microstructures induced by differences in strain of only a few percent. Moreover, GOS distributions are well correlated with the local values of strain as illustrated in Figure 8. In fact, in the range $\varepsilon=0.05$ to 0.3 , GOS average values increase almost linearly with respect to strain. At $\varepsilon=0.05$ and below, GOS values are too close to the measurement accuracy, so variations cannot be reasonably interpreted. Similar considerations can be made about the evolution of the GOS standard deviation (i.e., the width of the GOS distribution).

After annealing, the grain size in strained samples evolves as shown in Figure 9 and Table II. In the sample deformed up to $\varepsilon=0.05$, the microstructure remains relatively stable during annealing: few isolated bigger grains appear, but the overall microstructure does not evolve very much. Notably, the average grain size $(7.3 \mu \mathrm{m})$ and the level of intragranular misorientation are very close to those before annealing. Nonetheless, the possible recovery effects could not be assessed from the GOS map in such weakly strained sample. In the sample strained up to $\varepsilon=0.3$, bigger and strain-free grains appear, resulting from metadynamic or static recrystallization. As the level of strain is still quite low, the number of growing nuclei is limited, leading to an increase of average grain size $(13.3 \mu \mathrm{m})$ in the upper region compared to the microstructure before annealing $(4 \mu \mathrm{m})$. In the lower region of the same EBSD map where $\varepsilon=0.2$, the number of growing nuclei is consistently lower, leading to a slightly bigger grain size $(17 \mu \mathrm{m})$.

The most interesting microstructure gradient is found in the sample deformed up to $\varepsilon=0.1$. In this case, the final microstructure is much more heterogeneous and it clearly appears to be very sensitive to the degree of the local strain. In the upper region where the strain is close to $\varepsilon=0.1$, the microstructure is almost homogeneous, composed mostly by one overgrown grain population with an average grain size of $47 \mu \mathrm{m}$ and still few fine grains $(6.2 \mu \mathrm{m})$. However, in the lower region where the strain is close to $\varepsilon=0.07$, there are clearly two populations of fine and overgrown grains, respectively, with average grain sizes of 6.2 and $53 \mu \mathrm{m}$. Moreover, coarser grains contain many twins and intragranular $\delta$ phase particles (see Figure 10). It is worth emphasizing that such heterogeneous microstructure cannot be explained as a case of overall grain coarsening that is controlled by the distribution of the secondary-phase particles. As it is shown in Figure 5, the final grain size where the local strain is either $\varepsilon=0.1$ or $\varepsilon=0.07$ greatly exceeds the Smith-Zener limit. In other words, the occurrence of overgrown grains cannot be related only to the overall fraction and size of secondary-phase particles.

As it will be discussed in Section IV, such heterogeneous microstructure is very likely due to the discontinuous growth of few grains, a phenomenon that can be referred to as selective grain growth, and is comparable to abnormal grain growth with regard to the resulting bimodal grain size distribution. It could also be referred to as a static recrystallization phenomenon, with regards to the stored energy being the main driving force.

Figure 11 summarizes the influence of the local level of strain on the grain size after $\delta$ sub-solvus annealing. It shows that "critical" strains $(0.05<\varepsilon<0.1)$ can produce a dramatic increase of grain size, ten times bigger than that of the initial microstructure.

\section{Selective Grain Growth Evolution}

As indicated above, selective grain growth that has been observed in sample $\varepsilon=0.1$ after $\delta$ sub-solvus annealing at $1258 \mathrm{~K}\left(985^{\circ} \mathrm{C}\right)$ is not yet fully under- 


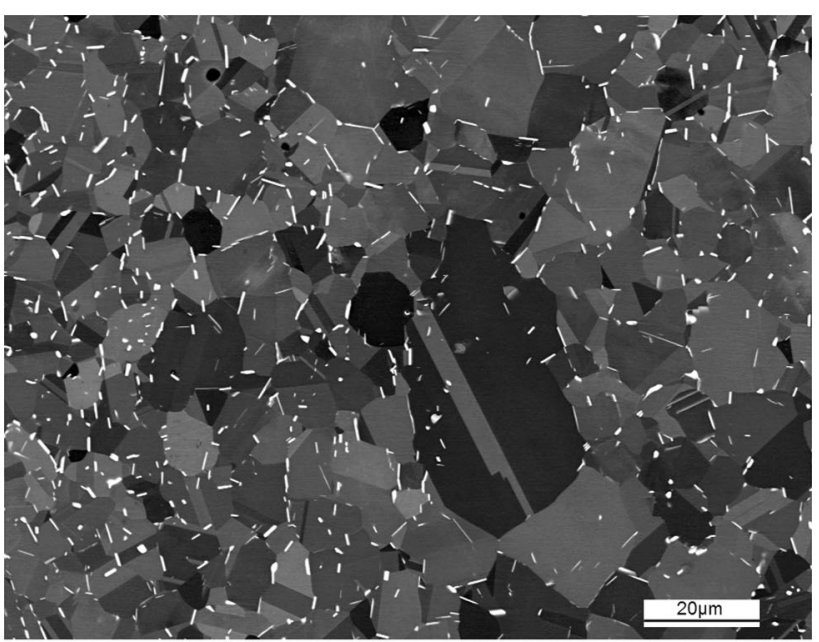

(a)

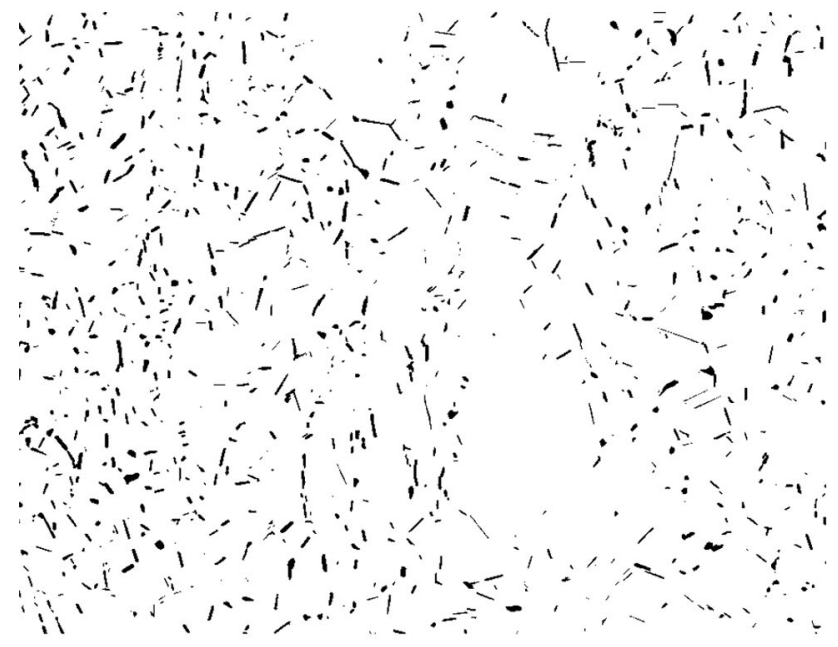

(b)

Fig. 6-Grain bigger than the Smith-Zener limit in the initial microstructure after $\delta$ sub-solvus annealing for $2 \mathrm{~h}$ : (a) BSE image, (b) $\delta$ phase filtered.

stood. Hence, an additional sample $(\varepsilon=0.1$-bis $)$ was produced by applying the same cycle used for sample $\varepsilon=0.1$, followed by a $\delta$ sub-solvus annealing at $1258 \mathrm{~K}$ $\left(985^{\circ} \mathrm{C}\right)$ for only 15 minutes. The microstructure obtained is displayed in Figure 12. Once again, grain evolution is strictly dependent on the local level of strain: in fact, at the bottom or center of the map (where the strain is lower), almost no grain evolution occurs. On the contrary, at the top of the map almost all of the fine initial grains that are deformed and hardened are replaced by few coarse strain-free grains that have grown after 15 minutes at $1258 \mathrm{~K}\left(985^{\circ} \mathrm{C}\right)$. These results confirm that small local variations of strain (of the order of $\Delta \varepsilon=0.02$ ) do influence the kinetics of selective grain growth in that critical strain range. Moreover, the absence of large grains at the bottom of the image after 15 minutes of annealing (while they were found to appear after two hours of annealing as seen in Figure 9(b)) suggests that they could arise from a nucleation process, involving an incubation period during which dislocations rearrangements occur. Addi- tional experiments must be carried out to investigate this possibility.

\section{FACTORS CONTRIBUTING TO THE SELECTIVE GRAIN GROWTH PROCESS}

It is well known from literature that abnormal grain growth (also called secondary recrystallization) may be initiated during annealing of microstructures when normal grain growth is inhibited (e.g., by the presence of particles) and/or certain grains enjoy some growing advantage over their neighbors. For example, few bigger grains due to broad initial grain size distributions, ${ }^{\text {11] }}$ higher mobility boundaries due to texture, ${ }^{[12]}$ or lower energy boundaries ${ }^{[13]}$ can give rise to the phenomenon. Moreover, several studies ${ }^{[14-16]}$ have reported that also small prior strains $(\varepsilon<0.1)$ can produce abnormal grain growth during annealing both in single-phase materials and in alloys containing second-phase particles. In fact, it remains questionable if in this case the phenomenon can still be considered a case of abnormal grain growth (driven by capillarity).

Now, since in the case under study strain stored energy appears to be the main parameter controlling the selective grain growth, the phenomenon should probably be better treated as a primary recrystallization process (driven by stored energy). However, it is not possible to exclude that also the classical factors producing abnormal grain growth may contribute as well.

Hence, the most probable factors for abnormal grain growth which could occur in the sample deformed up to $\varepsilon=0.1$ are investigated in the following sections.

\section{A. Grain size Advantage}

The critical conditions leading to abnormal grain growth of an assembly of grains with equal boundary energies and mobilities have been derived by Humphreys from a 3D mean field model of grain growth driven by capillarity forces. Based on such model, Figure 13 provides the minimum grain size ratio $\left(X=\frac{D_{\mathrm{MAX}}}{D}\right)$ required for a grain of size $D_{\mathrm{MAX}}$ to grow abnormally in a microstructure of average size $D$ : it shows that as the pinning term $\left(\psi=\frac{3 f D}{4 r}\right)$ increases, the minimum grain size ratio increases as well, so that for $\psi>1$ an infinite grain is required to produce abnormal growth. ${ }^{[8]}$ It is worth noting that when this model is used to evaluate the limiting grain size of a microstructure in equilibrium with a population of particles, it yields the same relation of Eq. [1] with $\alpha=0.25$. The experimental point corresponding to the sample $\varepsilon=0.1$ falls indeed in the area where abnormal grain growth could be initiated by a grain size advantage. However, also the point corresponding to $\varepsilon=0$ falls in the same area even if abnormal grain growth did not take place during annealing in this sample. In fact, the real pinning pressure is probably higher than the one estimated by the parameter $\psi$, which is calculated assuming a random distribution of spherical particles. In reality, particles have more complex shapes and they are mostly located on grain boundaries. Moreover, during annealing new $\delta$ 

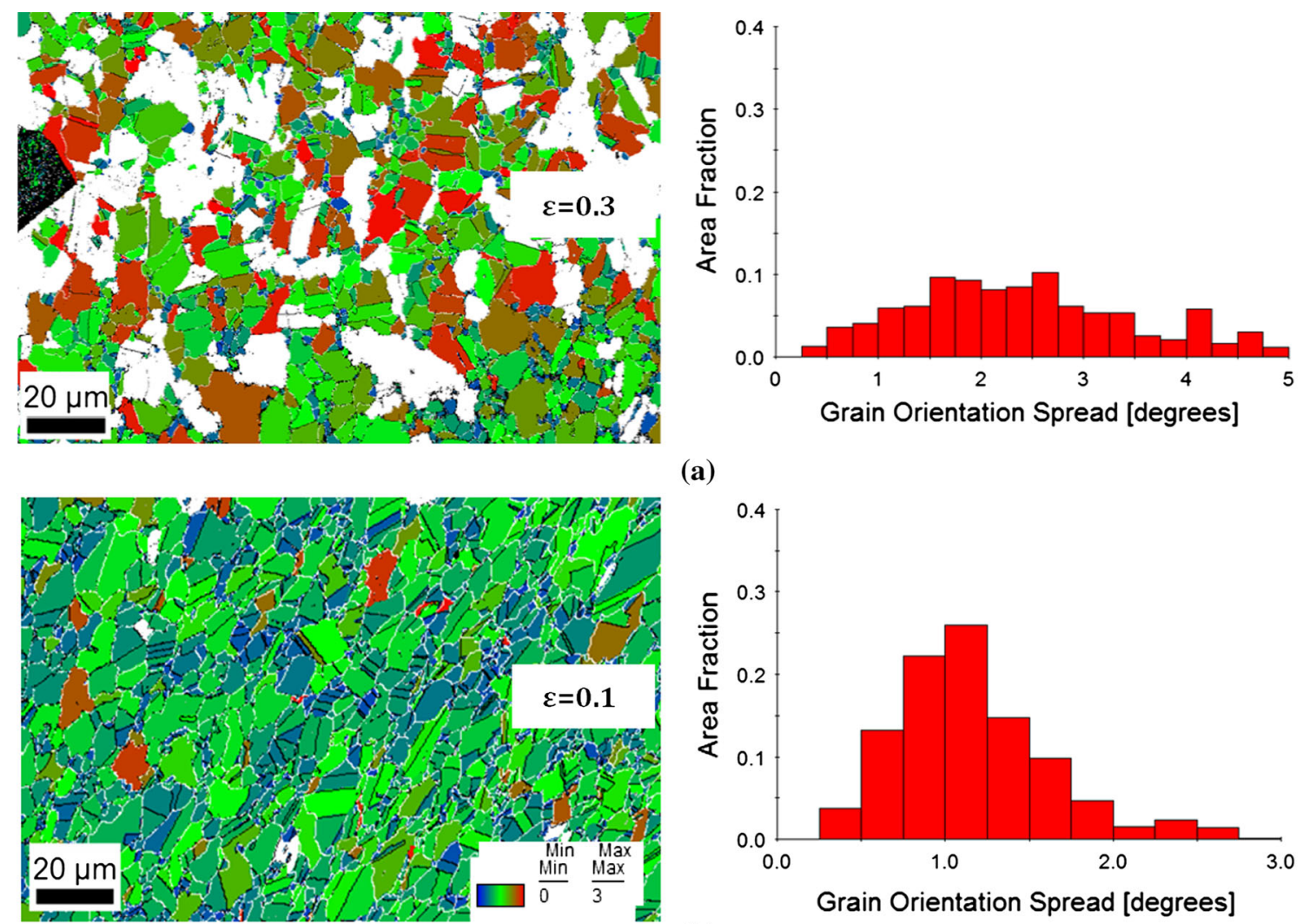

(a)

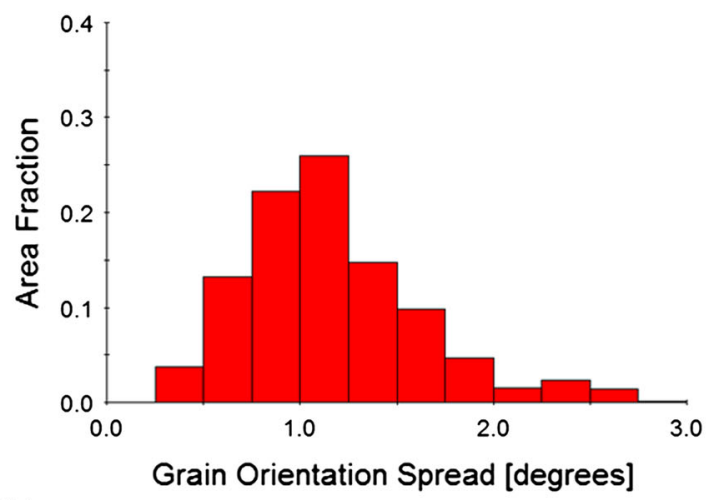

(b)
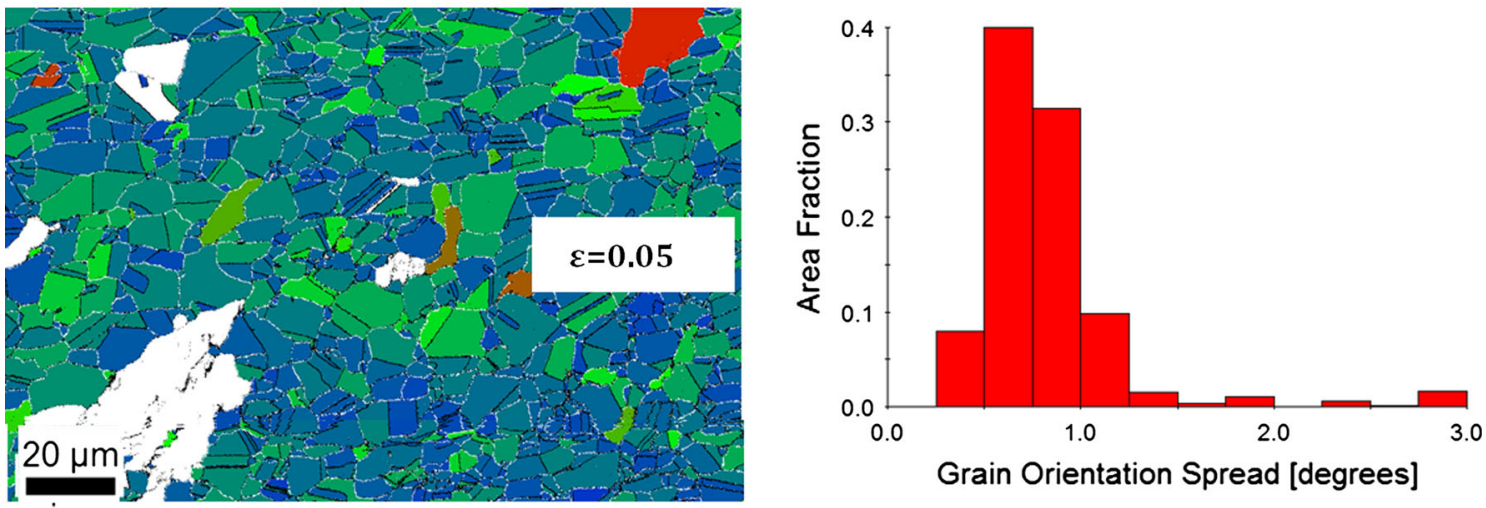

(c)

Fig. 7-Grain orientation spread (GOS) maps and distributions (area fraction) in the strained samples before annealing as a function of local equivalent strain: $(a) \varepsilon=0.3,(b) \varepsilon=0.1$ and $(c) \varepsilon=0.05$. In GOS maps, the grain boundaries are in white, the twins are in black, and white grains have GOS values higher than $3 \mathrm{deg}$.

phase particles precipitate and grow, increasing the pinning pressure. Finally, even if in principle the grain size advantage may produce abnormal grain growth in sample $\varepsilon=0.1$, it is unlikely to be the reason for the phenomenon in this case. Indeed, the grain size distribution is not affected by the application of $\varepsilon=0.1$; hence, it cannot be the reason for the different behaviors after annealing of samples $\varepsilon=0$ or $\varepsilon=0.1$.

\section{B. Grain Boundary Mobility or Energy Advantage}

The presence of a strong texture may also trigger abnormal grain growth, as a result of anisotropy in the grain boundary mobility and/or energy. More precisely, the growth of the few grains whose crystallographic orientation is different from the main texture component is promoted since there is a higher probability for these grains to have high-angle grain boundaries, which exhibit higher mobility. Such phenomenon has been observed only in strongly textured materials. ${ }^{[12]}$ Figure 14 shows the $\{100\}$ pole figure of sample $\varepsilon=0.1$ before annealing: the maximum pole density is very low $(<2$ m.r.d., multiple of a random distribution), implying that the texture is close to a random one even at the small scale of an EBSD map. Hence, abnormal grain growth is not likely to be produced by texture effects either. 


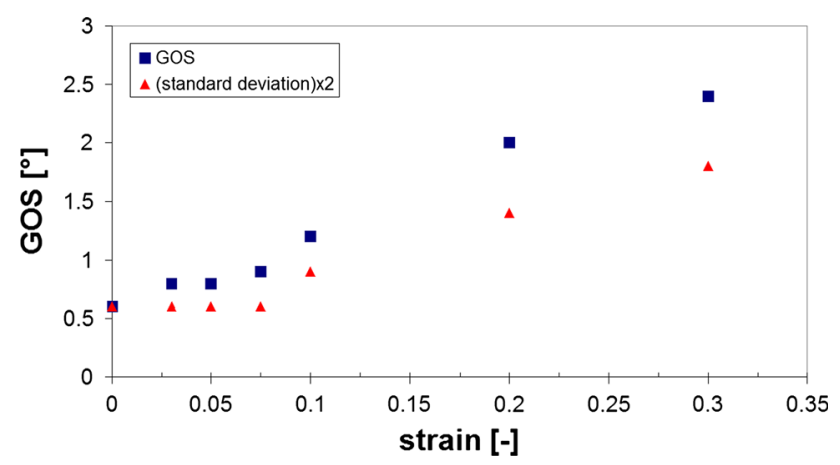

Fig. 8- Correlation between strain and average or standard deviation of GOS histograms.

The presence of lower energy grain boundaries (usually verifying a specific crystallographic misorientation relationship) may also lead to abnormal grain growth. If some boundaries exhibit a lower energy compared to general random boundaries, they promote the growth of grains having these low energy boundaries, which often correspond also to special grain boundary planes. Once again, such phenomenon is supposed to occur only in strongly textured materials, otherwise the "special" misorientation is lost once the first neighboring grains are consumed. However, it is worth noting that even in non-textured materials, the presence of "complexions" (which are particular configurations of the atomic structure of the interface at grain boundaries) may also lower the energy of few grain boundaries, producing abnormal grain growth. ${ }^{[17]}$ The analysis of the crystallographic misorientation of grain boundaries between overgrown and fine grains in sample $\varepsilon=0.1$ did not provide any evidence for the influence of crystallographic effects on abnormal grain growth in this case. More precisely, the abnormal/normal grain boundaries are mostly random high-angle boundaries.

\section{Stored Energy Advantage}

As detailed previously, the phenomenon under study is very unlikely to be due to one of the cases of abnormal grain growth described so far. However, the effect of low strains seems to play an important role in this case. Supposing that the GOS parameter can describe semiquantitatively the energy stored in grains, then Figure 7 shows that strain stored energy is distributed heterogeneously in the microstructure of the sample strained to $\varepsilon=0.1$ before annealing. In addition, it reveals that after annealing few low energy grains grew selectively despite Smith-Zener pinning at the expense of higher energy grains pinned by particles (Figures 9, 10 and 12). The plausibility of this scenario can be quantitatively assessed by estimating the three driving and pinning forces which govern grain boundary migration: the capillarity force, the force resulting from a stored energy difference across a grain boundary and the Smith-Zener pinning force.

\section{Estimation of the competing forces}

If the boundary migrates driven by the capillarity effect, then the driving pressure $\left(P_{\mathrm{G}}\right)$ can be expressed as ${ }^{[8]} P_{\mathrm{G}}=\gamma k$, where $\gamma$ is the grain boundary energy $\left(0.6 \mathrm{~J} / \mathrm{m}^{2}\right.$ at $1273 \mathrm{~K}\left(1000{ }^{\circ} \mathrm{C}\right)$ for pure nickel,$^{[18]}$ but it is worth noting that alloying elements should decrease this value $^{[19]}$ ) and $k$ is its mean curvature. In the case of spherical grains of radius $R, k=\frac{2}{R}$ and so $P_{\mathrm{G}}=\frac{2 \gamma}{R}$. However, in real microstructures, grains have different shapes and the effective driving force is found to be much lower when compared to the case of spherical grains. Based upon experimental observations on different (pure) materials, the relation between the mean grain size radius $(\mathrm{R})$ and the effective driving force was estimated as ${ }^{[20,21]}$

$$
P_{\mathrm{G}}=\frac{\gamma}{4 R} .
$$

If a grain boundary separates two grains of different stored energy, then the driving pressure $\left(P_{\mathrm{R}}\right)$ is equal to the difference of the energies per unit volume: ${ }^{[8]}$

$$
P_{\mathrm{R}}=\Delta E \text { with } E=0.5 \rho_{\mathrm{TOT}} G b^{2},
$$

where $G$ is the shear modulus $(45 \mathrm{GPa}$ at $1273 \mathrm{~K}$ $\left(1000{ }^{\circ} \mathrm{C}\right)$ ) and $b$ is the Burgers vector $(0.25 \mathrm{~nm})$. The total density of dislocations ( $\left.\rho_{\mathrm{TOT}}\right)$ is the sum of geometrically necessary (GND) and statistically stored (SSD) dislocations: $\rho_{\mathrm{TOT}}=\rho_{\mathrm{GND}}+\rho_{\mathrm{SSD}}$. The density of GNDs in a grain is linked to intragranular misorientation and the local density (at the scale of a pixel) can be estimated to a first approximation from EBSD data, provided that the EBSD step size is suitably chosen:[22]

$$
\rho_{\mathrm{GND}}^{\text {local }}=\frac{K}{b} \frac{\theta}{x},
$$

where $\theta$ is the misorientation angle between two pixels separated by a distance $x$. The parameter $K$ depends on the postulated dislocation structure, that in practice may depend on straining conditions: it was proposed $K=1$ for the bending ${ }^{[23]}$ and $K=2$ for the torsion ${ }^{[24]}$ of a cylinder, assuming the presence of tilt and twist rotations, respectively. Since the present study is based on torsion tests, $k=2$ was chosen.

If neighboring pixels are considered, then $x$ is the measuring step size. The value of $\theta$ can also be averaged over all pairs of pixels taken at a fixed distance $x$ from the point of interest, then the average value of $\theta$ is the kernel average misorientation (KAM) provided by the commercial EBSD software packages. In the present work, it was chosen to consider instead the grain average misorientation parameter (GAM), that is, the average value of the KAM value in a grain (calculated between neighboring pixels, i.e., $x$ is equal to the measuring step). The GAM value was preferred because it is a grain property instead of a pixel property as for the KAM. Then, the average GND density of a grain is calculated as

$$
\rho_{\mathrm{GND}}^{\mathrm{grain}}=\frac{K}{b} \frac{G A M}{x} .
$$

Moreover, as a rough estimation, it will be considered that the density of GNDs is a constant fraction of the total density of dislocations, i.e.,

$$
\rho_{\mathrm{TOT}}=s \cdot \rho_{\mathrm{GND}},
$$



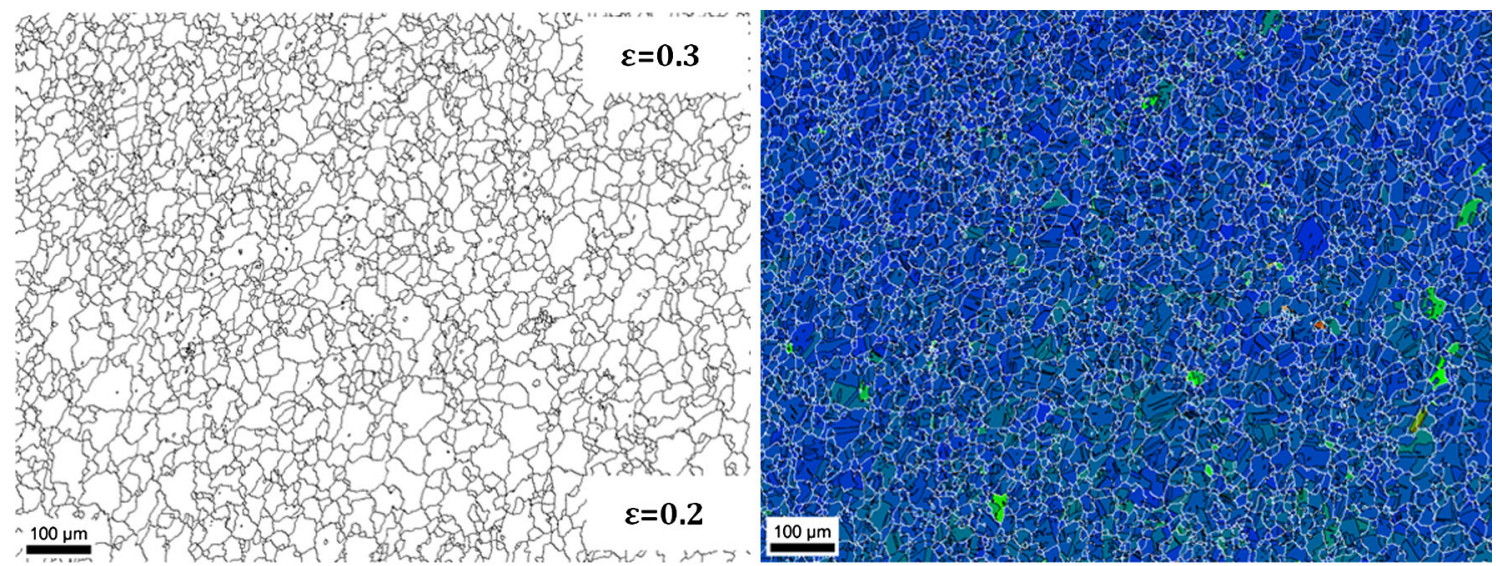

(a)
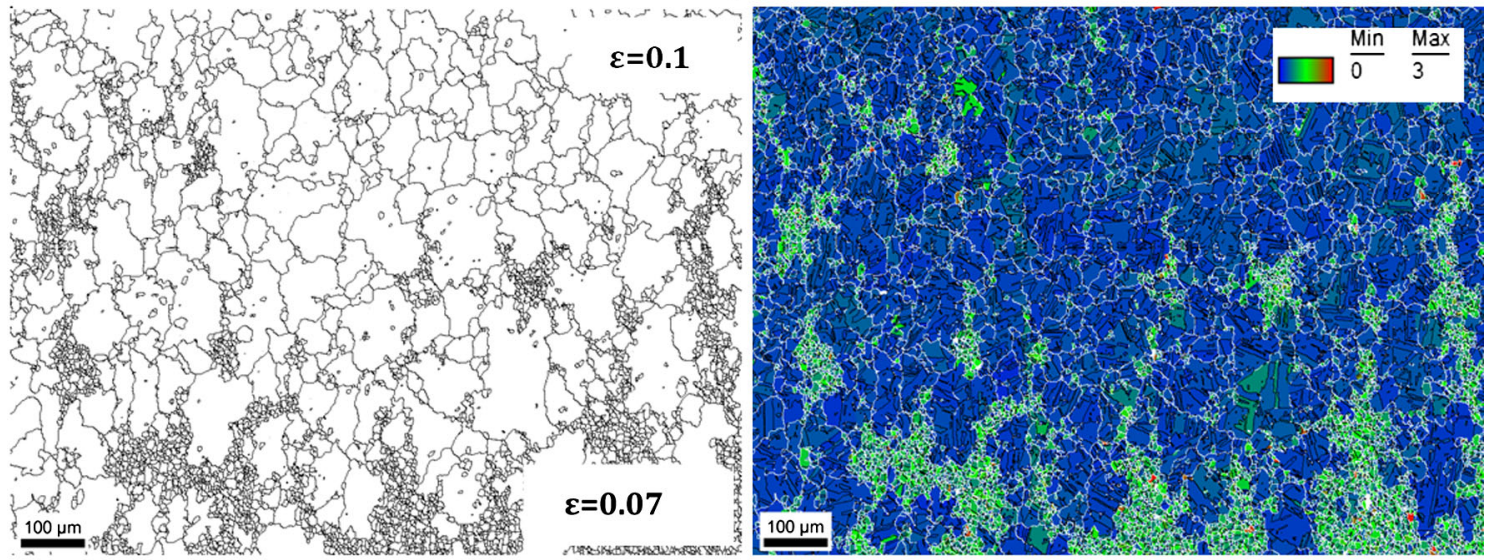

(b)
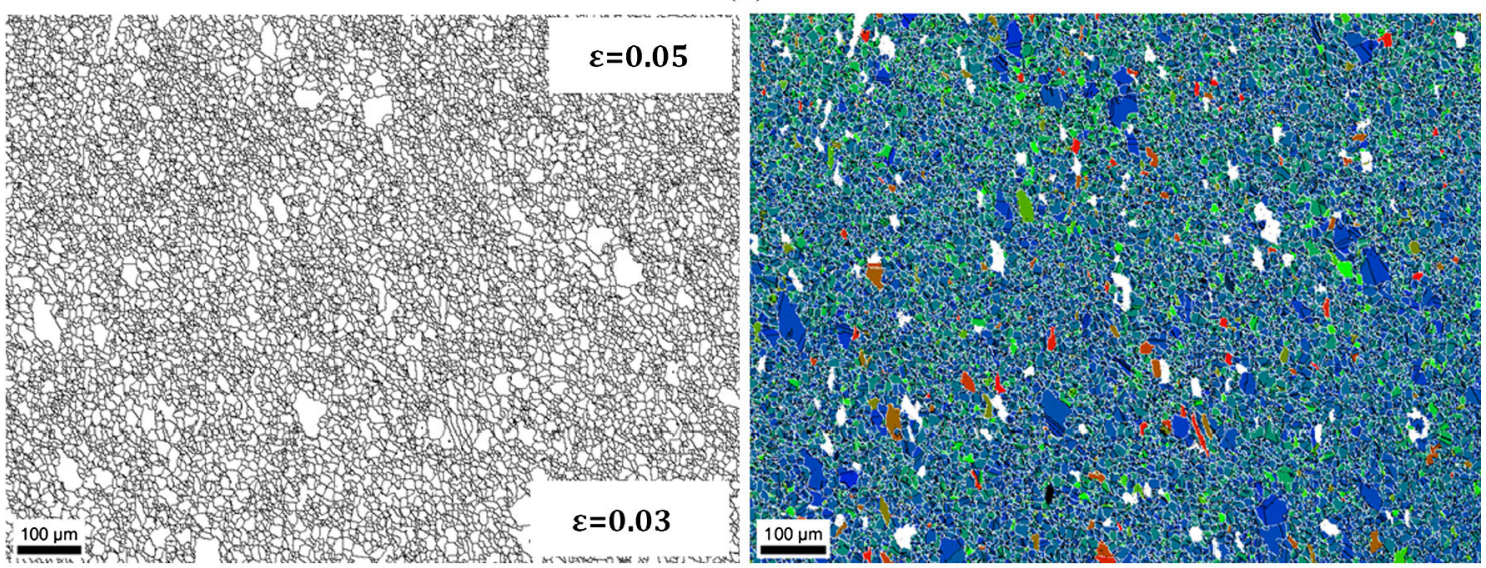

(c)

Fig. 9-Microstructures after $\delta$ sub-solvus annealing for $2 \mathrm{~h}$ in samples characterized by different initial levels of strain: $(a) \varepsilon=0.3,(b) \varepsilon=0.1$, (c) $\varepsilon=0.05$. Left images display EBSD maps only with grain boundaries in black, and right images show grain orientation spread (GOS) maps with grain boundaries in white and twins in black. Note: white grains have GOS values higher than 3 deg.

where $s$ is a positive constant parameter higher than 1 taking into account the presence of additional statistically stored dislocations. This undermines the principle that the SSDs density would increase linearly with the GNDs density. Finally, if $s=1$, only GNDs are considered. If $s=2$, then it is supposed that 50 pct of dislocations are SSDs. If $s=4$, then 75 pet of dislocations are SSDs.
The presence of secondary-phase particles of radius $(r)$ and volume fraction $(f)$ hinders boundary migration, exerting a pinning pressure $\left(P_{\mathrm{P}}\right)$ that can be expressed according to the Smith-Zener assumptions as ${ }^{[8]}$

$$
P_{\mathrm{P}}=\frac{3 \gamma f}{2 r} \text {. }
$$


It is noted that such a formula probably underestimates the real pinning pressure. ${ }^{[20]}$

\section{Results}

As already pointed out, strain-induced selective grain growth supposedly involves the growth of few lower energy grains at the expense of higher energy grains pinned by particles. Such lower energy grains are possibly either already present in the initial microstructure or they form by nucleation.

In the following, only the contribution of GNDs to strain energy is taken into account (i.e., $s=1$ in Eq. [6]). Hence, strain stored energy estimations are indeed lower with respect to real values.

Table III reports the estimation of driving forces for grain boundary migration in sample strained to $\varepsilon=0.1$

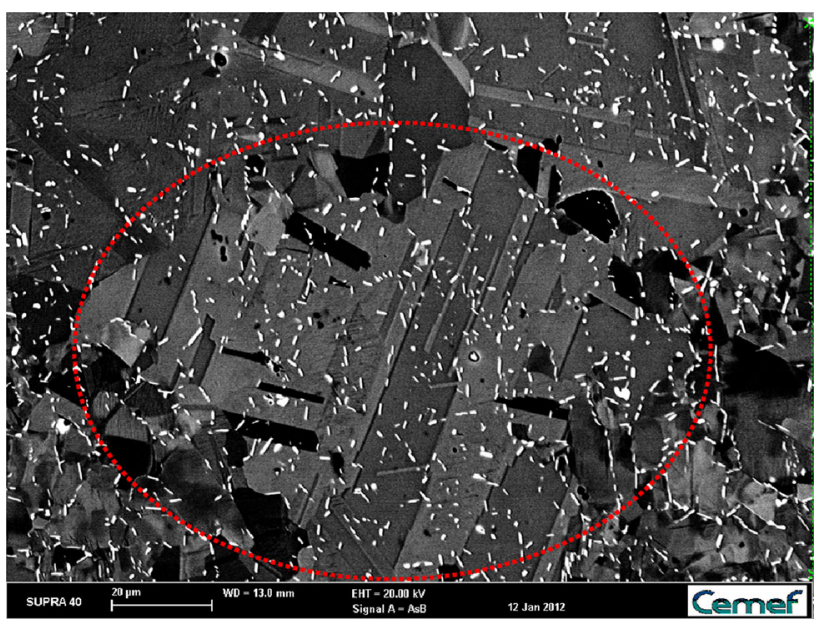

Fig. 10-BSE image of an overgrown grain in sample $\varepsilon=0.1$ after annealing. assuming that lower energy grains are already present in the microstructure. If strain energy is not taken into account, then the microstructure does not coarsen due to particle pinning that is higher than the capillarity force. However, if a stored energy difference per unit volume of at least $20 \mathrm{kPa}$ exists across a grain boundary, then grain boundary motion can be initiated. Now, a driving pressure of $20 \mathrm{kPa}$ corresponds to a difference of $\mathrm{GAM} / x$ between neighbor grains of only $0.1 \mathrm{deg} /$ $0.8 \mu \mathrm{m}$. Such a small GAM $/ x$ difference is beyond the angular resolution of the EBSD technique under the actual settings; however, it is still worth looking at the fraction of boundaries separating two crystals with a $\mathrm{GAM} / x$ difference of at least $0.4 \mathrm{deg} / 0.8 \mu \mathrm{m}$ (considering $0.4 \mathrm{deg}$ as the GAM difference that can be measured with confidence). Figure 15 displays the histogram of the fraction of boundaries separating two crystals with a fixed GAM $/ x$ difference. Such histogram is calculated using a dataset (provided by the OIM software) which reports for each crystal the value of GAM/ $x$ and the list of neighboring grains. Hence, it is possible to calculate the fraction of boundaries separating two crystals with a given GAM $/ x$ difference.

Now, Figure 15 illustrates that the fraction of boundaries separating two crystals with a GAM $/ x$ difference of at least $0.4 \mathrm{deg} / 0.8 \mu \mathrm{m}$ in sample $\varepsilon=0.1$ is about 30 pct; by comparison, in the sample deformed up to $\varepsilon=0.05$ the fraction is only about 15 pct. These results confirm that small stored energy differences, which can initiate the growth of some grains that exceed the Smith-Zener limit, are indeed present in the microstructure before annealing. Moreover, the probability to initiate the growth of a grain increases with strain, as the fraction of boundaries separating two crystals with a given $\mathrm{GAM} / x$ difference increases as well. It was indeed observed that the number fraction of overgrowing grains is raising (and accordingly their size is decreasing) when the prior strain increases.

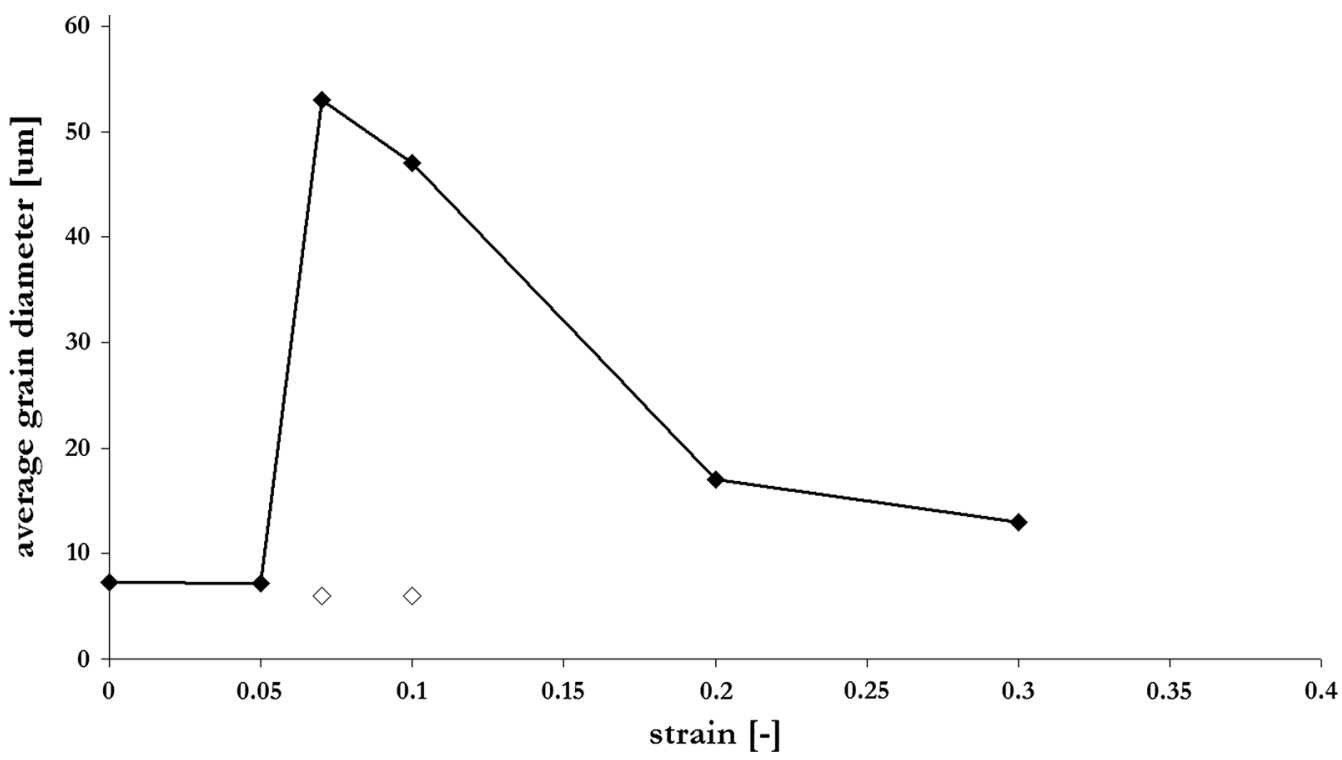

Fig. 11-Influence of local strain on final grain size after $\delta$ sub-solvus annealing for $2 \mathrm{~h}$ in samples characterized by different initial levels of strain. Empty squares correspond to the minor population of bimodal microstructures. 


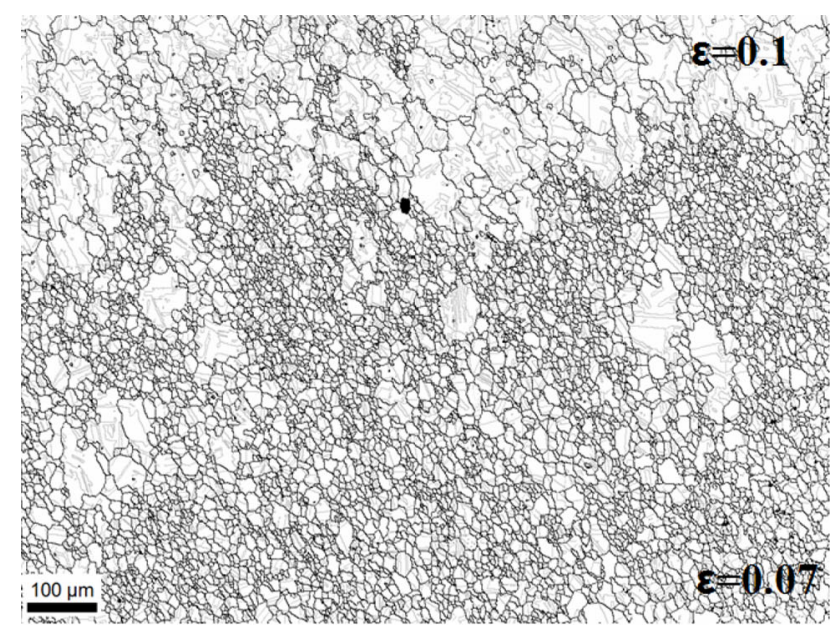

(a)

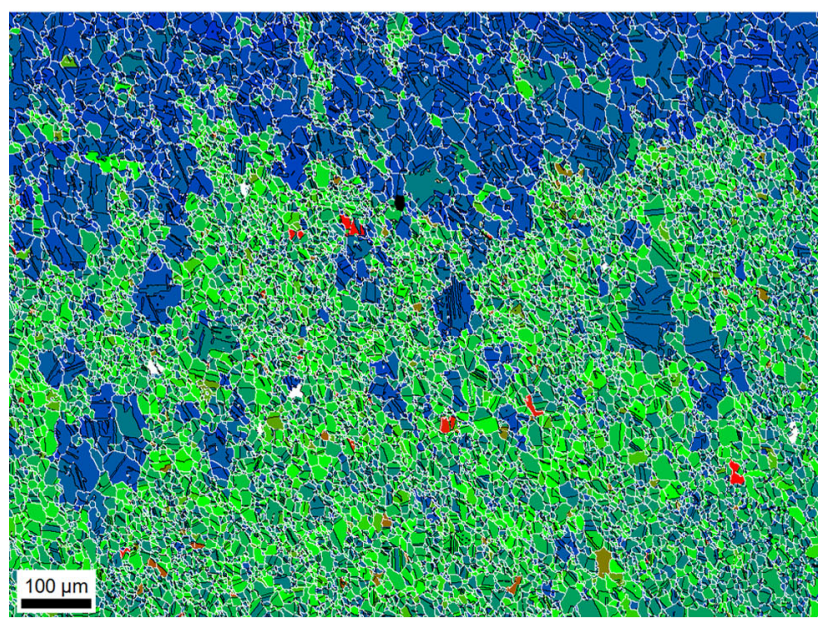

(b)

Fig. 12-Microstructure after $\delta$ sub-solvus annealing for $15 \mathrm{~min}$ of sample $\varepsilon=0.1$-bis. EBSD map showing grain boundaries in black and twins in gray $(a)$ and related map of grain orientation spread (GOS) maps with grain boundaries in white and twins in black (b) Note: white grains have GOS values higher than $3 \mathrm{deg}$.

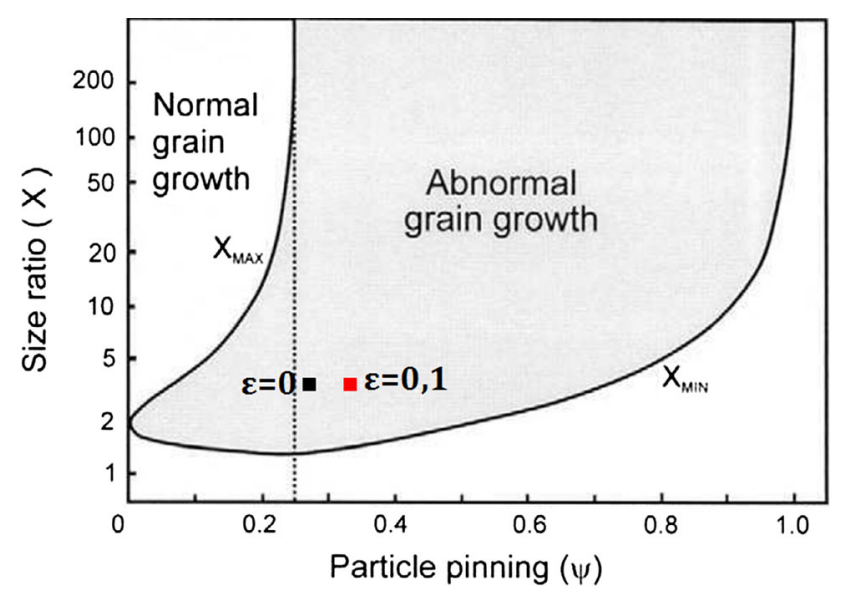

Fig. 13-Plot from ${ }^{[8]}$ of minimum grain size ratio (X) to trigger abnormal grain growth as a function of Smith-Zener pinning $(\psi)$ : microstructures of samples $\varepsilon=0$ and $\varepsilon=0.1$ fall in the area where abnormal grain growth is possible.

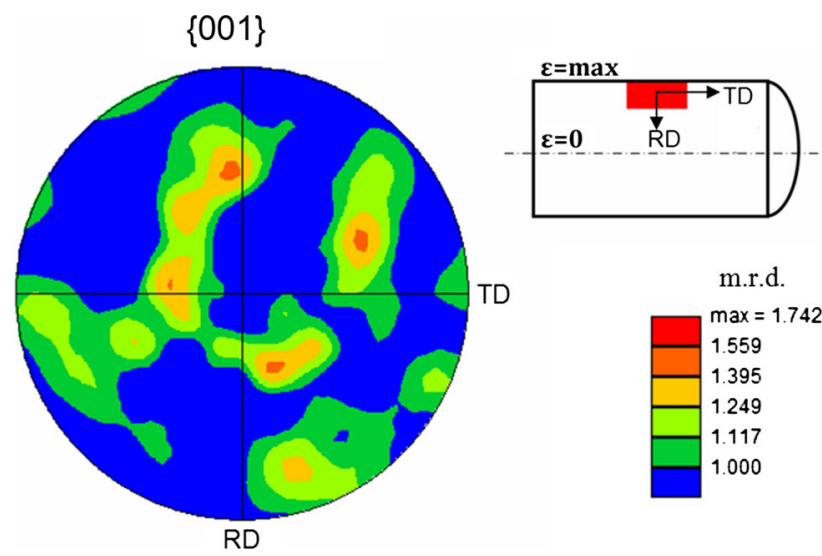

Fig. 14 - Pole figure of planes $\{001\}$ measured by EBSD on sample $\varepsilon=0.1$ before annealing: the torsion axis (TD) is horizontal and the radial direction $(\mathrm{RD})$ is vertical.

It is interesting to consider also the scenario where few strain-free nuclei would nucleate during annealing and would then overgrow (see Table IV). The size of a nucleus was assumed to be $1 \mu \mathrm{m},{ }^{[8]}$ and hence, SmithZener pinning was not considered since the size of the nucleus is smaller than the average distance between $\delta$ phase particles (i.e., several microns). Table IV indicates that a nucleus may grow only by bulging into a grain having a GAM/x of $1.2 \mathrm{deg} / 0.8 \mu \mathrm{m}$. Now, Figure 16 shows that grains having a GAM $/ x$ value higher than $1.2 \mathrm{deg} / 0.8 \mu \mathrm{m}$ are indeed present in both samples $\varepsilon=0.1$ and $\varepsilon=0.05$. Then, it is possible that nuclei form, coarsen, and eventually grow abnormally. Moreover, as already pointed out, the minimum GAM $/ x$ value necessary to counterbalance the capillarity force of a nucleus is calculated taking into account only the contribution of GNDs to strain energy, i.e., considering an underestimated value of stored energies. Hence, even grains having a $\mathrm{GAM} / x$ value lower than $1.2 \mathrm{deg} /$ $0.8 \mu \mathrm{m}$ may be consumed by a nucleus.

In conclusion, the estimation of the three driving forces governing grain boundary migration confirms that their orders of magnitude are compatible with the selective growth of low energy grains against the SmithZener pinning pressure, including if those low energy grains are small ones arising from a nucleation process. Thus, these grains may have two different origins: either they were recrystallization nuclei or they were already present in the microstructure before annealing.

It is nevertheless worth mentioning that the dependence of the fraction of concerned grains on strain is fully compatible with the nucleation process: the higher the strain, the higher the nucleation density, and the smaller the resulting grain size. The incubation time pointed out in Section III-D is also in favor of such a mechanism. Yet, further dedicated experiments are required to definitely demonstrate that static nucleation occurs in Inconel 718 after such low straining. But whatever their origin, the reason why the low energy grains can overgrow is their low dislocation density (or stored energy). 
Table III. Comparison of Driving Forces and Pinning Force in the Sample Strained Up to $\varepsilon=0.1$ for the Growth of Existing Grains

Pressure $(\mathrm{kPa})$

Estimation

Threshold for Grain Growth

Pinning (Eq. [7], $r=0.25 \mu \mathrm{m}, f=2.2 \mathrm{pct}$ )

Capillarity (Eq. [2], $2 R=4.6 \mu \mathrm{m})$

$-90$

GND stored energy (Eq. [3], $\Delta \mathrm{GAM} / 0.8 \mu \mathrm{m}>0.1 \mathrm{deg} / 0.8 \mu \mathrm{m}]$

$>20$

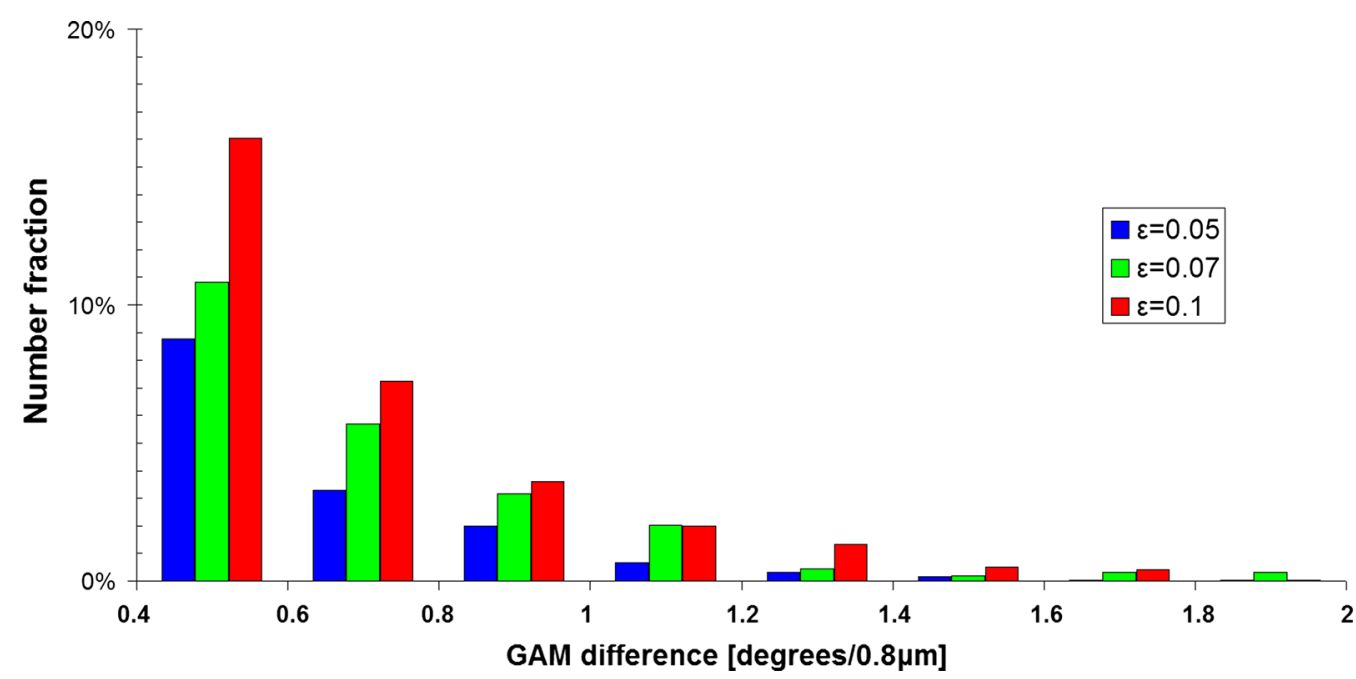

Fig. 15-Histogram of the fraction of grain and twin boundaries separating two crystals with a fixed GAM difference in samples strained up to $\varepsilon=0.05$ and $\varepsilon=0.1$. The fraction of boundaries corresponding to a GAM difference lower than $0.4 \mathrm{deg} / 0.8 \mu \mathrm{m}$ is not displayed.

Table IV. Comparison of Driving Forces and Pinning Force in the Sample Strained Up to $\varepsilon=0.1$ for the Growth of Strain-Free Nuclei

\begin{tabular}{lcr}
\hline & \multicolumn{2}{c}{ Pressure (kPa) } \\
\cline { 2 - 3 } & Estimation & Threshold for Grain Growth \\
\hline Capillarity (Eq. [2], $2 R=1 \mu \mathrm{m})$ & -300 & $>300$ \\
GND stored energy (Eq. [3], $\Delta \mathrm{GAM} / 0.8 \mu \mathrm{m}>1.2 \mathrm{deg} / 0.8 \mu \mathrm{m})$ & \\
\hline
\end{tabular}

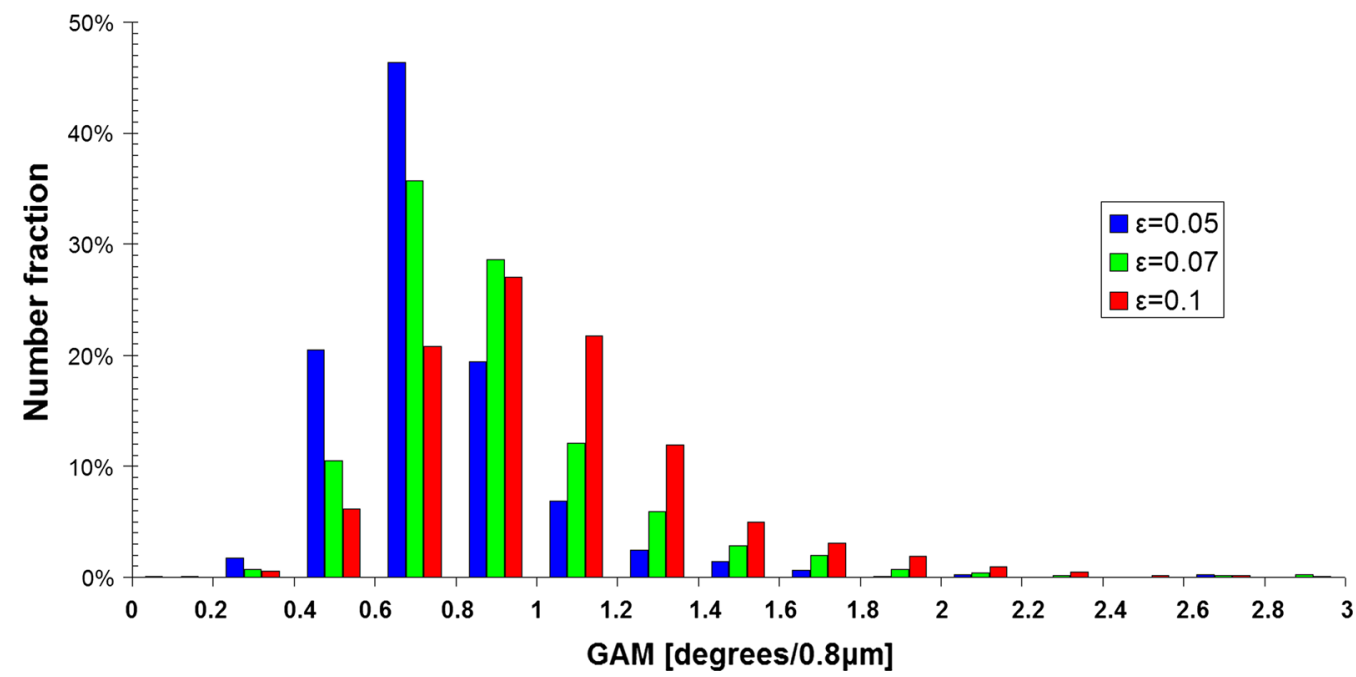

Fig. 16 - GAM distribution (number fraction) of all crystals (i.e., individual GAM values are calculated for each crystal in a twinned grain) in samples strained up to $\varepsilon=0.05$ and $\varepsilon=0.1$. 


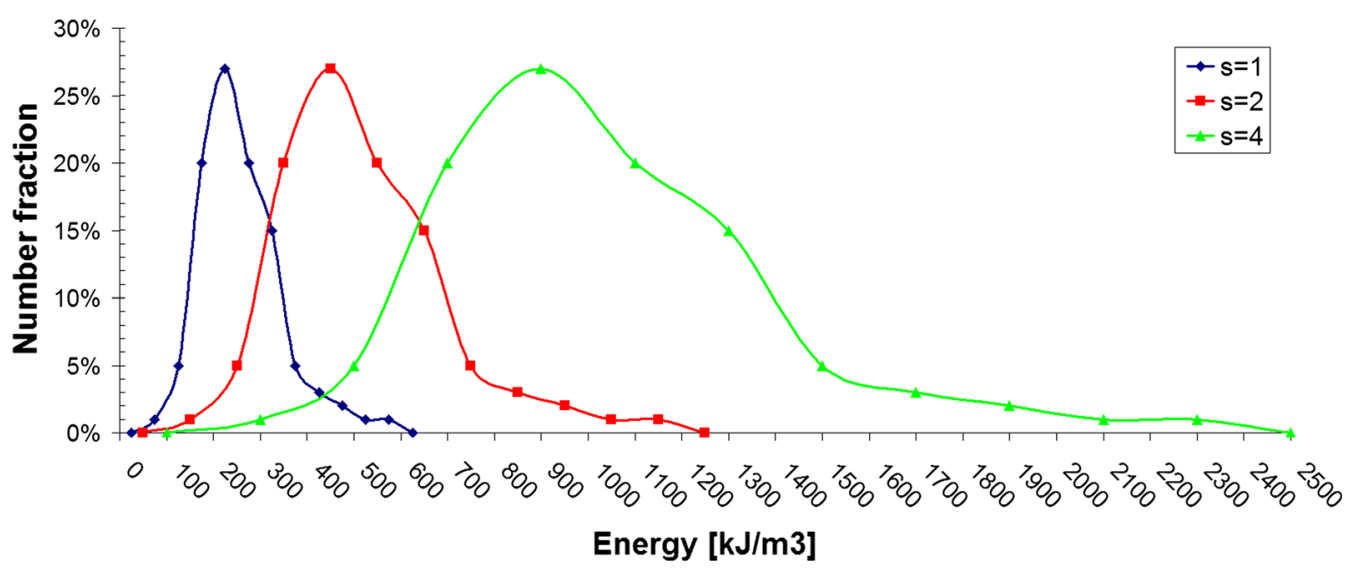

Fig. 17- Strain stored energy distribution of sample $\varepsilon=0.1$ before annealing. The parameter $s$ is introduced to take into account the energy contribution of statistically stored dislocations.

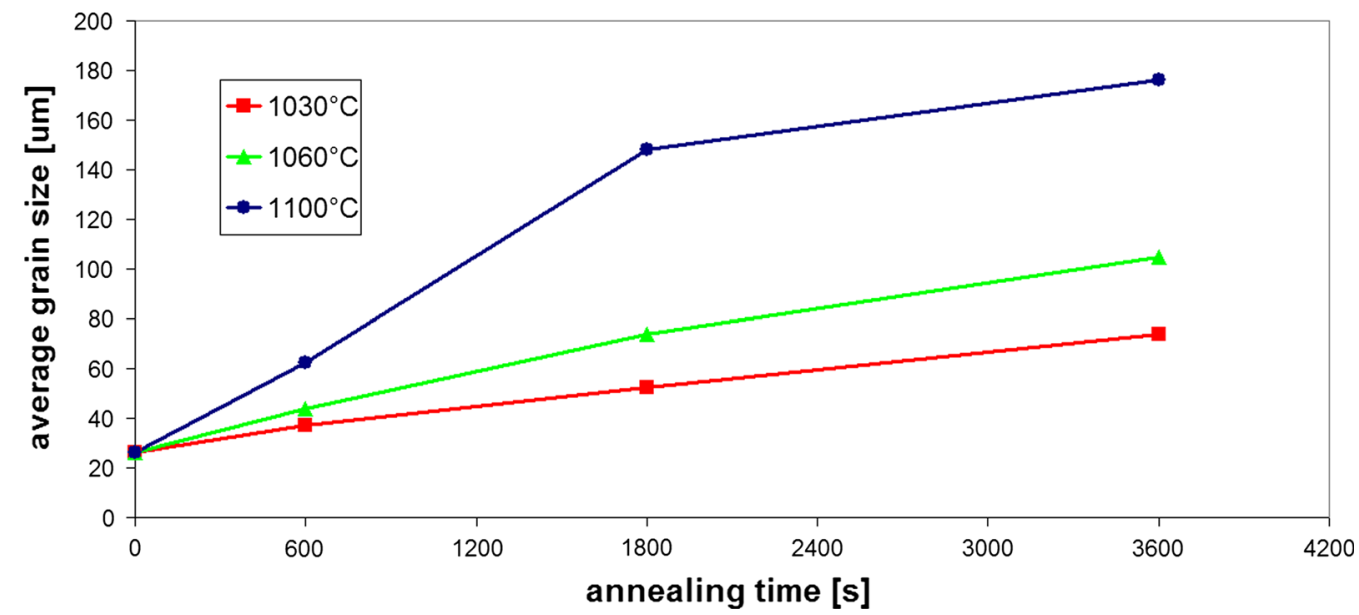

Fig. 18 - Grain size evolution during $\delta$ super-solvus annealing at different temperatures of Inconel 718 samples.

\section{NUMERICAL SIMULATION OF STRAIN- INDUCED ABNORMAL GRAIN GROWTH}

Experimental analyses provided the evidence that small prior strains produce selective grain growth overcoming the Smith-Zener pinning pressure during annealing. Intragranular misorientation (GOS, GAM) data suggest that low strains induce critical strain stored energy distributions: as a consequence, few lower energy grains grow at the expense of higher energy grains pinned by particles. In this section, numerical modeling is exploited to test if the strain energy distributions estimated from EBSD measurements in sample $\varepsilon=0.1$ can initiate the abnormal growth of lower energy grains (assuming that nucleation does not take place, but low energy grains arising from a nucleation process would behave the same).

\section{A. Estimation of Strain Energy Distribution}

The GAM distribution of sample $\varepsilon=0.1$ before annealing was already shown in Figure 16. Such a distribution can be converted into the average density of dislocations per grain using Eqs. [5] and [6]. Then, using Eq. [3], it is possible to estimate the average stored energy per grain. Figure 17 shows the strain energy distribution of sample $\varepsilon=0.1$ as a function of the parameter $s$ : if $s$ increases, histograms widen and shift toward higher values.

\section{B. Numerical Model}

The numerical model used in this work allows one to simulate microstructure evolution, taking into account Smith-Zener pinning, capillarity and stored energy driven grain growth in a single framework. It is based on a level set description of interfaces in the context of a finite element formulation coupled with an anisotropic meshing and remeshing strategy. This approach was already used to simulate both $2 \mathrm{D}$ and $3 \mathrm{D}$ primary recrystallization ${ }^{[25]}$ and grain growth ${ }^{[26]}$ in the presence of second-phase particles. ${ }^{[27]}$

In the following, microstructure evolution is simulated in a 2D system; hence, the numerical results cannot be directly compared to the experimental ones (that are 


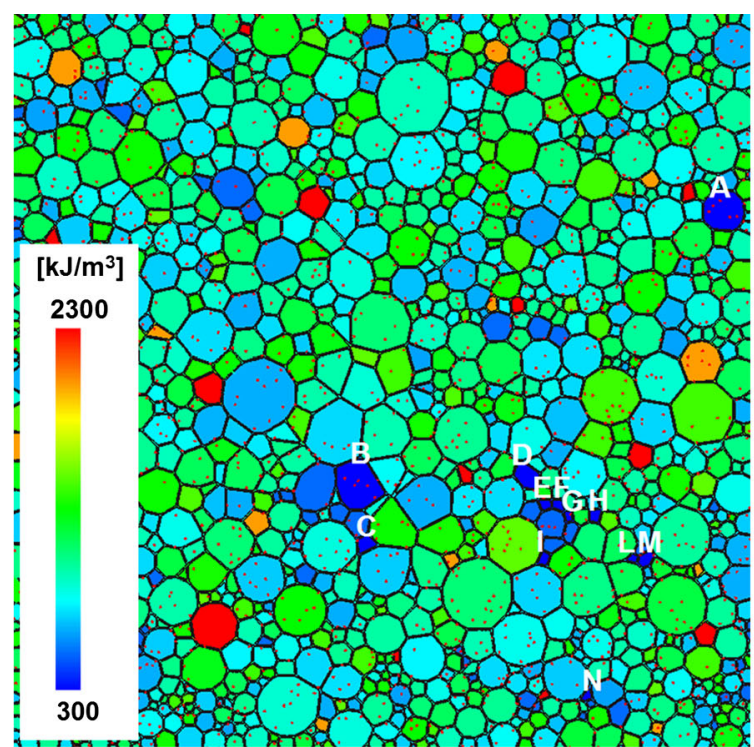

(a)

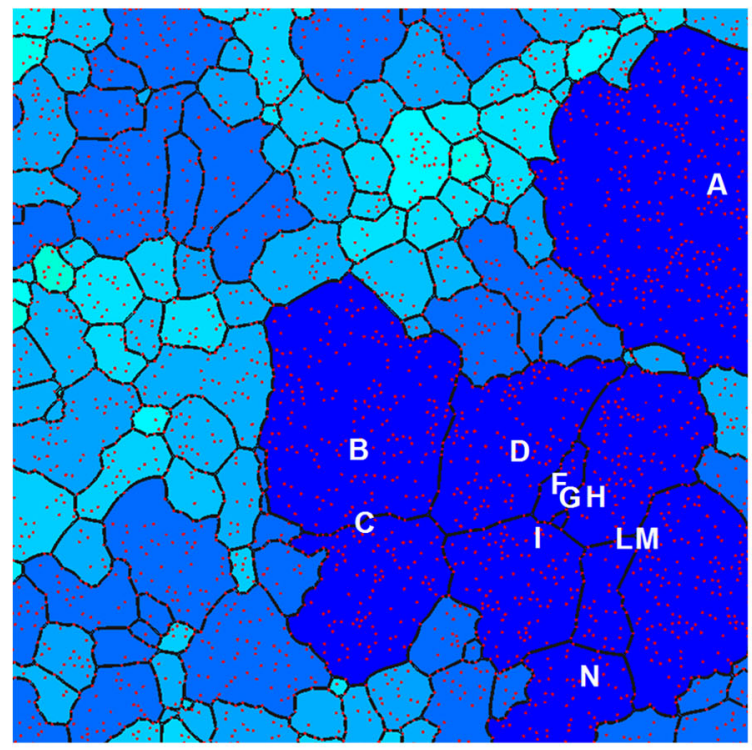

(c)

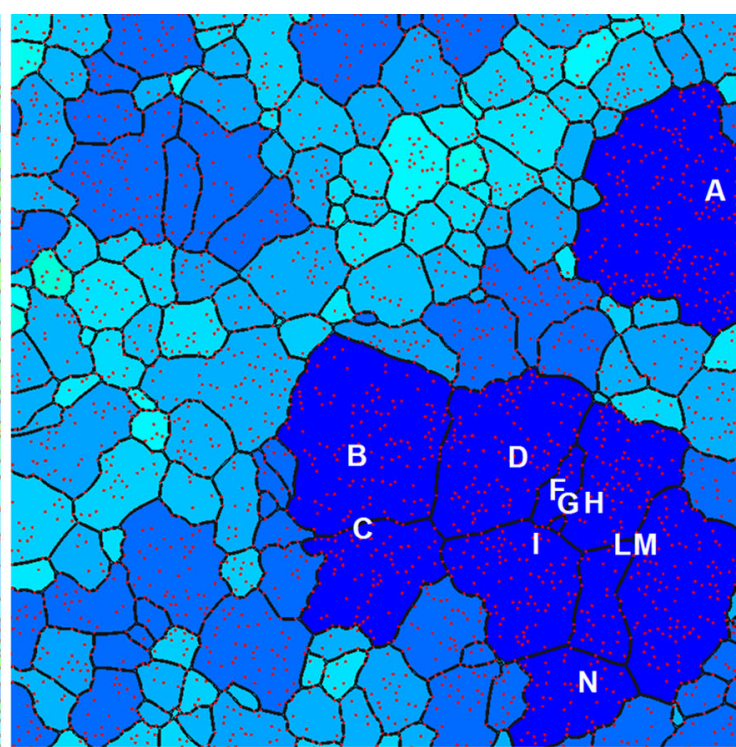

(b)

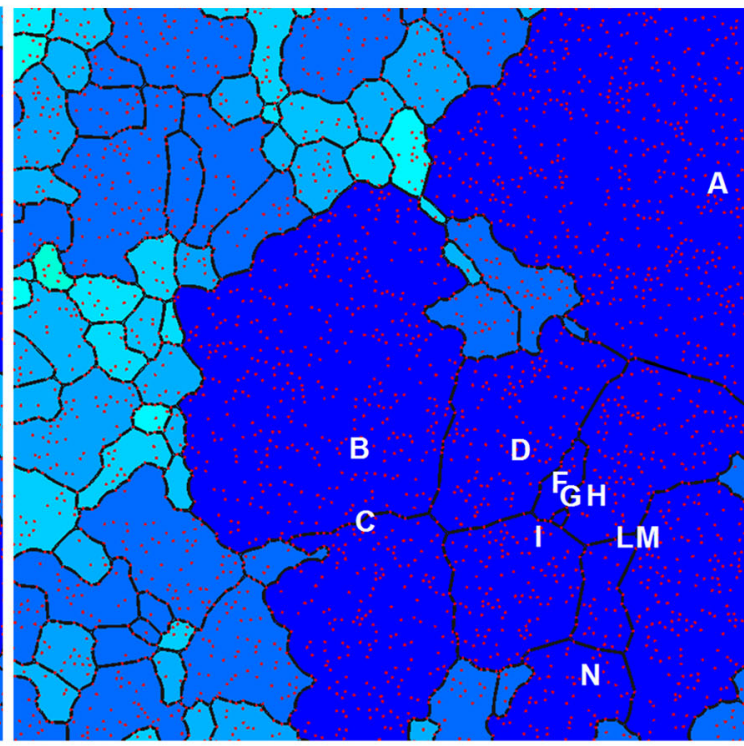

(d)

Fig. 19-Evolution of a microstructure with an initial energy distribution equivalent to that of Fig. $17(s=4)$ and a particle fraction equivalent to 4 pet after annealing at $1258 \mathrm{~K}$ for different times: initial microstructure $(a), 300 \mathrm{~s}(b), 600 \mathrm{~s}(c)$, and $900 \mathrm{~s}(d)$.

indeed linked to the evolution of 3D systems). Nonetheless, 2D numerical simulation is able to test the validity of the proposed mechanism for microstructure evolution and to test the influence of microstructural parameters. The size of the simulation domain is $200 \mu \mathrm{m}$ by $200 \mu \mathrm{m}$, and it contains circular particles of radius $=0.4 \mu \mathrm{m}$ and surface fraction equal to 4 pct. The average grain size of the initial microstructure is equal to $6 \mu \mathrm{m}$ (about 1100 grains) and the initial strain energy distribution is that of Figure 17 with $s=4$. Constant values of grain boundary mobility $(M)$ and energy $(\gamma)$ are chosen as close as possible to the grain boundary properties of Inconel 718 at the $\delta$ sub-solvus temperature $1258 \mathrm{~K}$ $\left(985^{\circ} \mathrm{C}\right)$. The value of grain boundary energy is set to $\gamma=0.6 \mathrm{~J} / \mathrm{m}^{2}$. The value of grain boundary mobility is set to $M=2.3 \times 10^{-13} \mathrm{~m}^{4} /(\mathrm{J} \mathrm{s})$. Such value was extrapolated using experimental data describing the Inconel 718 grain size evolution during annealing at different temperatures (see Figure 18). The mobility at different $\delta$ super-solvus temperatures was estimated by fitting experimental data with the following relation (as found in ${ }^{8]}$ ) that links the growth rate of the average grain diameter of the microstructure $(D)$ with the grain boundary mobility $(M)$ and the capillarity driving pressure defined in Eq. [2]:

$$
\frac{\mathrm{d} D}{\mathrm{~d} t}=2 M P_{\mathrm{G}}
$$

Then, the following Arrhenius-type equation ${ }^{[8]}$ was calibrated to extrapolate the mobility value at $1258 \mathrm{~K}$ $\left(985^{\circ} \mathrm{C}\right)$ : 


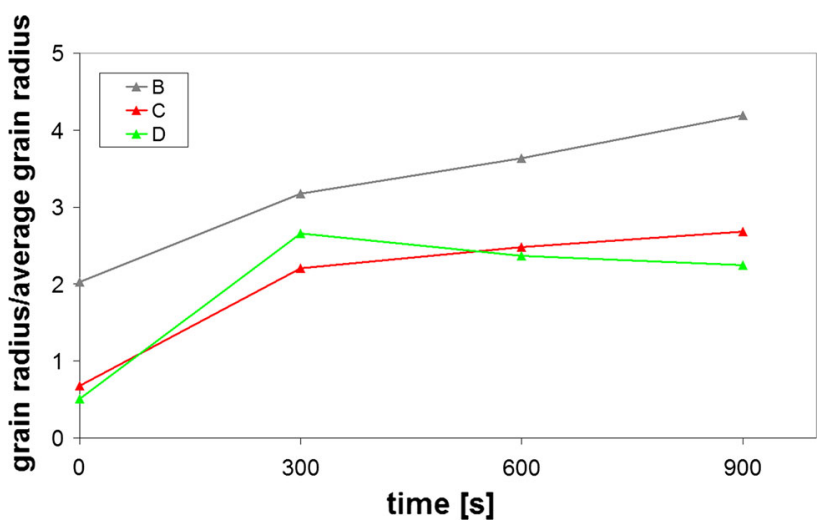

Fig. 20 - Grain size evolution of grains B, C, and D of Fig. 19.

$$
M=M_{0} \exp \left(\frac{-Q}{R T}\right),
$$

where $T$ is the temperature, $M_{0}=2981 \mathrm{~m}^{4} /(\mathrm{J} \mathrm{s})$, $Q=387 \mathrm{~kJ} /(\mathrm{mol} \mathrm{K})$, and $R=8.31 \mathrm{~J} /(\mathrm{mol} \mathrm{K})$.

It is worth noting that the extrapolation of the mobility value at $\delta$ sub-solvus temperatures from $\delta$ super-solvus data does not take into account the fact that in the $\delta$ super-solvus domain, all niobium atoms are in solid solution, while in the $\delta$ sub-solvus domain a fraction of niobium atoms are present in $\delta$ phase particles. Indeed, in the $\delta$ sub-solvus domain, less niobium atoms are in solid solution, which may affect the mobility value that was extrapolated from $\delta$ supersolvus data.

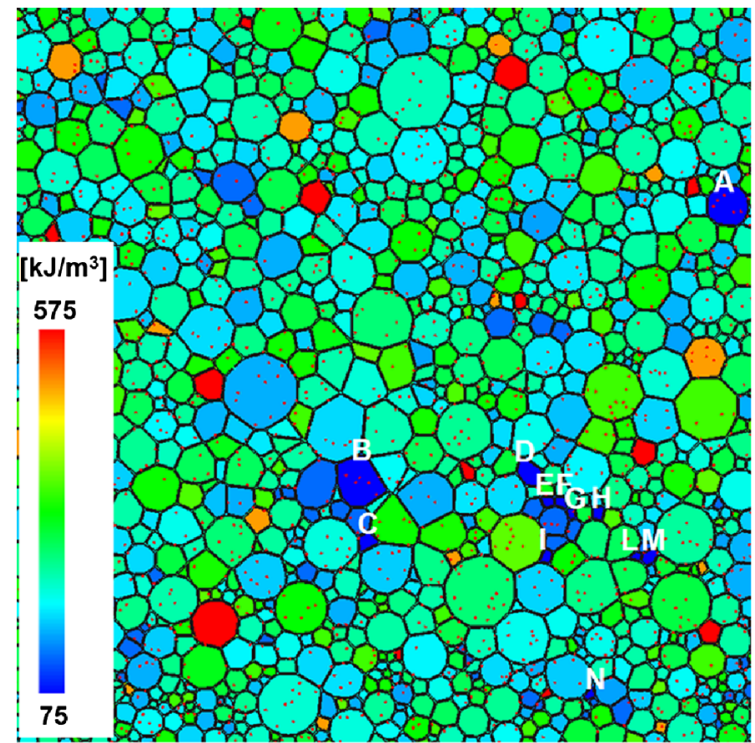

(a)

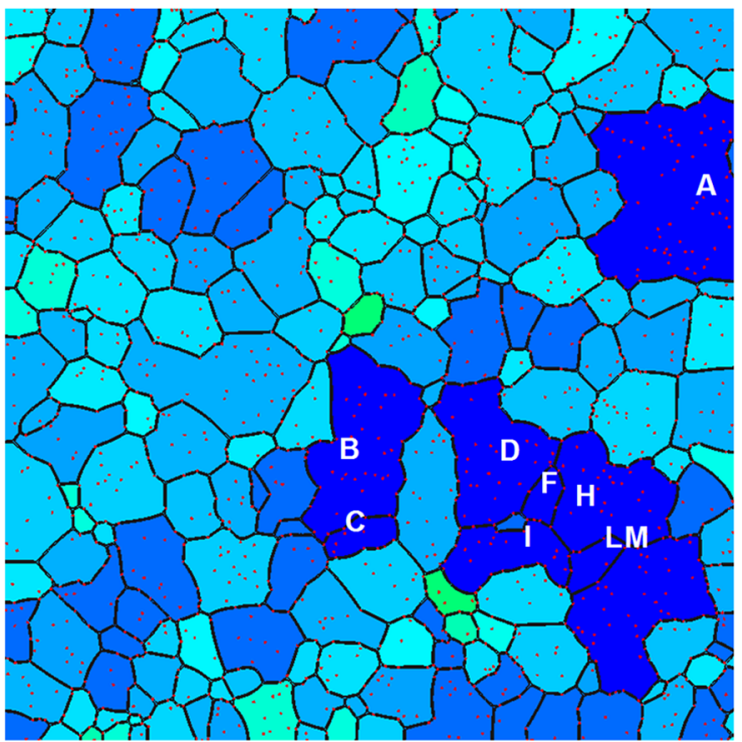

(c)

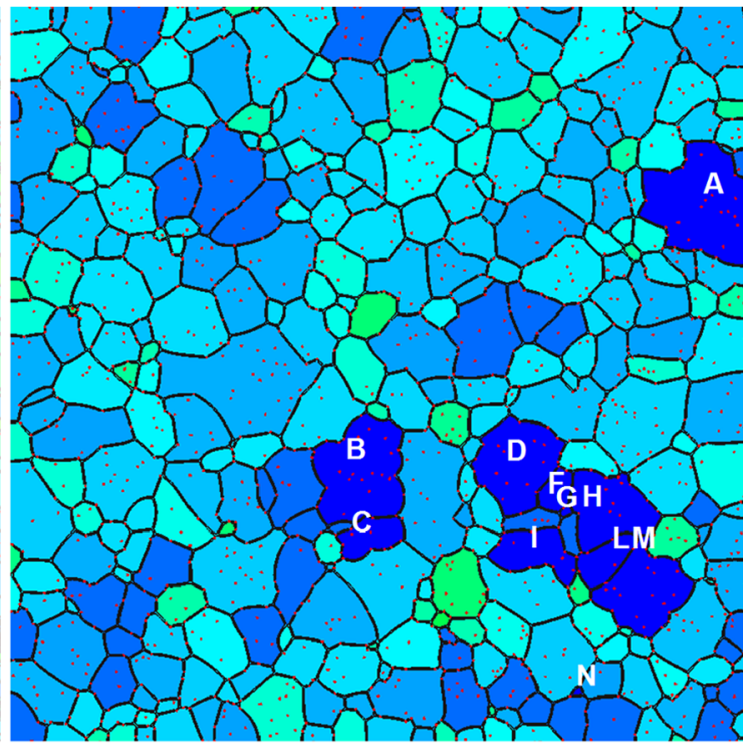

(b)

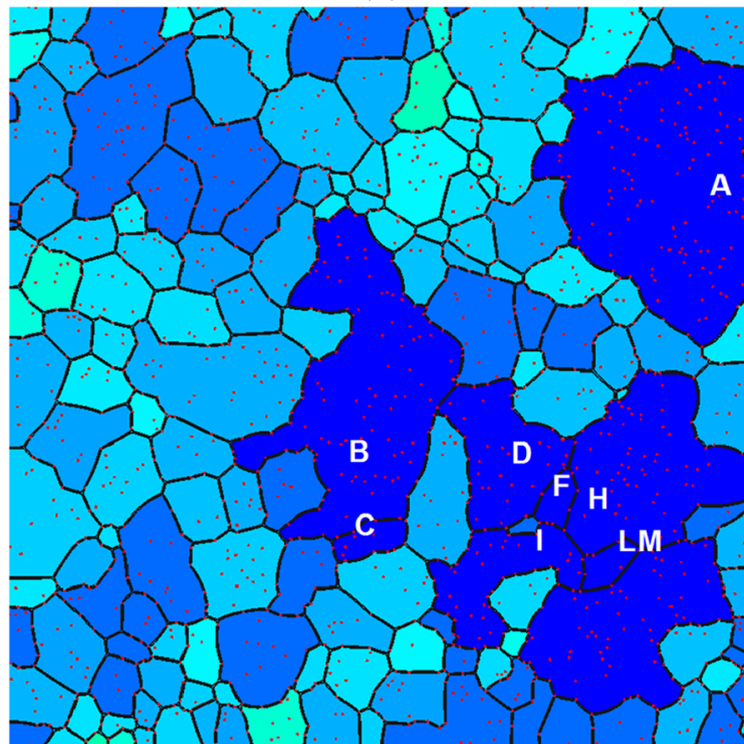

(d)

Fig. 21-Evolution of a microstructure with an initial energy distribution equivalent to that of Fig. $17(s=1)$ and a particle fraction equivalent to 2 pct after annealing at $1258 \mathrm{~K}\left(985^{\circ} \mathrm{C}\right)$ for different times: initial microstructure $(a), 300 \mathrm{~s}(b), 900 \mathrm{~s}(c)$, and $3300 \mathrm{~s}(d)$. 


\section{Simulation Results}

Figure 19 illustrates the simulation results of the annealing (at $1258 \mathrm{~K}\left(985^{\circ} \mathrm{C}\right)$ for 15 minutes) of the microstructure previously described. Overall, all grains coarsen up to 5 minutes; however, afterward most of them are pinned by particles, then they stop growing. However, the initially lowest energy grains (labeled by letters from $\mathrm{A}$ to $\mathrm{N}$ ) continue to grow even after 5 minutes. Some of them (A, B, or C) coarsen up to 15 minutes consuming neighboring higher energy grains, while all others stop growing as soon as they are mostly surrounded by equal energy grains. Indeed, Figure 20 indicates that grains $\mathrm{B}$ and $\mathrm{C}$ continue to grow abnormally as their growth rate remains higher than that of the assembly of grains, which are mostly pinned. Grain D initially grows abnormally, but then its growth stagnates as it impinges on equal energy grains.

Concerning the influence of the parameter $s$, it is important to note that if only GNDs are taken into account (i.e., $s=1$ ), then selective grain growth is not initiated in the simulation as all grains are pinned by particles. For example, Figure 21 shows that an initial strain energy distribution equal to that of Figure 16 with $s=1$ is not sufficient to initiate the phenomenon in a microstructure where the particle fraction is now equal to 2 pct. Indeed, grains A and B initially grow abnormally but then they stop growing as they impinge on equal energy grains. In fact, only higher values of $s$ can initiate abnormal grain growth as stored energy differences across boundaries increase: the higher the value of $s$, the faster the growth rate of the overgrowing grains.

Overall, these numerical results seem to support the proposed mechanism, which involves the growth of lower energy grains in a pinned microstructure and the sensitivity of the phenomenon to the initial stored energy distribution.

\section{CONCLUSIONS}

The critical microstructural parameter governing the stability during $\delta$ sub-solvus annealing in Inconel 718 is the deformation stored energy distribution with respect to the $\delta$ phase particles distribution.

In the absence of deformation stored energy, a fine microstructure $(5 \mu \mathrm{m})$ remains stable during annealing provided that the fraction of $\delta$ phase particles is higher than 1 pct (average particle size of 0.2 to $0.3 \mu \mathrm{m}$ ). This is fully consistent with the classical particle pinning model of Smith-Zener.

If strain is applied before annealing, then the microstructure becomes unstable and the final stable grain structure is governed by the level of applied strain. If the strain is higher than 0.1 , then an homogeneous but coarser microstructure ( 3 to 4 times compared to the initial grain size) is formed. In the critical range $0.05<\varepsilon<0.1$, selective grain growth leads to an heterogeneous microstructure formed by overgrown grains (ten times larger compared to the initial grain size) and fine pinned grains. This phenomenon is best interpreted as a case of strain-induced selective grain growth in a pinned microstructure leading to the possible formation of bimodal grain size distributions. Since stored energy provides the driving force for the phenomenon, it should also be regarded as a primary recrystallization phenomenon. The origin of those overgrowing grains can be either a nucleation process, or the presence of very few deformed grains in the microstructure before annealing. The dependence of the number fraction of those grains on strain is in favor of the nucleation hypothesis, but the latter could not be definitely demonstrated here. Whatever their origin, the reason for which these grains can overgrow is their energy advantage which allows them to overcome the Smith-Zener pinning pressure.

The validity of the proposed mechanism is furthermore corroborated by the numerical simulation of the phenomenon taking into account in a single framework a strain energy distribution estimated from EBSD data, capillarity, and particle pinning.

\section{REFERENCES}

1. M.L. Brogdon and A.H. Rosenberger: in Superalloys 2008: 11th International Symposium on Superalloys, TMS, R.C. Reed, K.A. Green, P. Caron, T.P. Gabb, M.G. Fahrmann, E.S. Huron, S.A. Woodward, eds., Warrendale, PA, 2008, pp. 583-88.

2. B. Flageolet, O. Yousfi, Y. Dahan, P. Villechaise, and J. Cormier: 7th International Symposium on Superalloy 718 and Derivatives, TMS, Wiley, Hoboken, NJ, 2010, pp. 595-606.

3. J.F. Uginet and B. Pieraggi: in Superalloys 718, 625, 706 \& Various Derivatives, E.A. Loria, ed., TMS, Warrendale, PA, 1997, pp. 343-52.

4. K. Song and M. Aindow: Mater. Sci. Eng. A, 2007, vol. 479, pp. $365-72$.

5. C.S. Smith: Trans. Metall. Soc. AIME, 1948, vol. 175, pp. 15-51.

6. G.D. Smith and H.L. Flower: in Superalloys 718, 625, $706 \&$ Various Derivatives, E.A. Loria, ed., TMS, Warrendale, PA,1994, pp. 355-64.

7. A. Agnoli, M. Bernacki, R. Loge, J.-M. Franchet, J. Laigo, and N. Bozzolo: in Superalloys 2012: 12th International Symposium on Superalloys, TMS, Wiley, Hoboken, NJ, 2012, pp. 73-82.

8. F.J. Humphreys and M. Hatherly: Recrystallization and Related Annealing Phenomena, Elsevier, Oxford, UK, 2004.

9. L. Vanherpe, N. Moelans, B. Blanpain, and S. Vandewalle: Comput. Mater. Sci., 2010, vol. 49, pp. 340-50.

10. M. Mujahid and M. Martin: J. Mater. Sci. Lett., 1994, vol. 13, pp. 153-55.

11. J. Dennis, P.S. Bate, and F.J. Humphreys: Acta Mater., 2009, vol. 57, pp. 4539-47.

12. M. Mujahid, C.A. Gater, and J.W. Martin: J. Mater. Eng. Perform., 1998, vol. 7, pp. 524-32.

13. D.K. Lee, B.J. Lee, K.J. Ko, and N.M. Hwang: Mater. Trans., 2009, vol. 50, pp. 2521-25.

14. J.B. Koo, D.Y. Yoon, and M.F. Henry: Metall. Mater. Trans. A, 2002, vol. 33A, pp. 3803-15.

15. T.A. Bennett, P.N. Kalu, and A.D. Rollett: Microsc. Microanal., 2011, vol. 17, pp. 1-6.

16. Y.K. Cho, D.K. Yoon, and M.F. Henry: Metall. Mater. Trans. A, 2001, vol. 32A, pp. 3077-90.

17. S.J. Dillon, M. Tang, W.C. Carter, and M.P. Harmer: Acta Mater., 2007, vol. 55, pp. 6208-18.

18. S.M. Foiles: Scr. Mater., 2010, vol. 62, pp. 231-34.

19. M. Hillert: Metall. Trans. A, 1977, vol. 8A, pp. 1431-38.

20. P.A. Manohar, M. Ferry, and T. Chandra: ISIJ Int., 1998, vol. 38, pp. 913-24.

21. B.R. Patterson and Y. Liu: Metall. Mater. Trans. A, 1992, vol. 23A, pp. 2481-82.

22. M. Calcagnotto, D. Ponge, E. Demir, and D. Raabe: Mater. Sci. Eng. A, 2010, vol. 527, pp. 2738-46. 
23. H. Gao: J. Mech. Phys. Solids, 1999, vol. 47, pp. 1239-63.

24. L. Kubin: Scr. Mater., 2003, vol. 48, pp. 119-25.

25. M. Bernacki, H. Resk, T. Coupez, and R.E. Logé: Modell. Simul. Mater. Sci. Eng., 2009, vol. 17.
26. M. Bernacki, R.E. Logé, and T. Coupez: Scr. Mater., 2011, vol. 64 , pp. 525-28.

27. A. Agnoli, N. Bozzolo, R.E. Logé, J-.M. Franchet, J. Laigo, and M. Bernacki: Comput. Mater. Sci., 2014, vol. 89, pp. 233-41. 